\title{
El estado de necesidad en el arbitraje de inversión: su invocación consuetudinaria y convencional en los arbitrajes Enron, Sempra, CMS, LG\&E y Continental ante el Centro Internacional de Arreglo de Diferencias relativas a Inversiones (CIADI)*
}

\author{
State of Necessity in Investment Arbitration: \\ Customary and Conventional Invocation of Necessity \\ in the Enron, Sempra, CMS, LG\&E and Continental \\ ICSID Arbitrations
}

\author{
Laura Victoria García Matamoros ${ }^{* *}$ \\ Walter Arévalo Ramírez ${ }^{* * *}$
}

\begin{abstract}
SUMARIO: I. Introducción. II. Codificación, alcance y naturaleza jurídica del estado de necesidad como causal de exclusión de ilicitud. III. La existencia del estado de necesidad en materia económica. IV. El Estado de necesidad como defensa del Estado en materia de Inversión: su controversial uso en el CIADI. V. La experiencia en los laudos del CIADI para la crisis argentina: lecciones sobre la aplicación de la defensa de la necesidad en el arbitraje bilateral de inversión. VI. Conclusiones. VII. Bibliografía mínima.
\end{abstract}

* El presente artículo es parte de los resultados de la línea de investigación "Derecho internacional y globalización”, del Grupo de Investigación en Derecho Internacional de la Facultad de Jurisprudencia de la Universidad del Rosario, dentro del Proyecto de investigación financiado en la Convocatoria 617/2013 de jóvenes investigadores de Colciencias (Instituto Colombiano de Ciencia y Tecnología).

** Profesora asociada y directora del Grupo de Investigación en Derecho Internacional de la Facultad de Jurisprudencia, Universidad del Rosario. E-mail: laura.garcia@urosario.edu.co. *** Profesor investigador de Derecho Internacional y miembro del Grupo de Investigación de Derecho Internacional de la Facultad de Jurisprudencia, Universidad del Rosario. E-mail: walter.arevalo@urosario.edu.co. 
RESUMEN: Este artículo pretende evidenciar el renovado debate sobre las causales de exclusión de ilicitud en la responsabilidad internacional del Estado en materia de compromisos económicos y, particularmente, realizar un aporte al entendimiento del concepto de estado de necesidad. Para ello, se acude a un conjunto particular de casos en el Centro Internacional de Arreglo de Diferencias Relativas a Inversiones. En este sentido, el análisis jurídico de este trabajo se construye con base en la distinción de la fuente a partir de la cual se invoca el estado de necesidad y en los efectos de esta diferenciación en cuanto a la carga de la prueba de la necesidad, al interés esencial del Estado que se ve afectado, al cálculo de daños y a la anulación de ciertos laudos por la incorrecta aplicación de tal causal.

Palabras clave: Centro Internacional de Arreglo de Diferencias relativas a Inversiones, estado de necesidad en derecho internacional, responsabilidad internacional del Estado por hechos internacionalmente ilícitos, causales de exclusión de ilicitud, tratados bilaterales de inversión.

ABSTRACT: The article studies, from the concept of necessity developed by international law, the developing debate of the state of economic necessity and the way it operates as a circumstance precluding wrongfulness in the doctrine of Responsibility of States for Internationally Wrongful Acts. The article analyses the developments on the topic in the ICSID. The study aims to contribute in the debate on the effectiveness of circumstances precluding wrongfulness in the presence of the State's financial commitments and tries to make a contribution to the understanding of "necessity". The article intents to identify the legal effects when invoking the doctrine of necessity, such as the burden of proof of the necessity, the identification of a essential interest of the State that is affected, its effects on the calculation of damages and the annulment of certain awards by the misapplication of such doctrine.

Key words: International Centre for Settlement of Investment Disputes, state of necessity in international law, responsibility of states for internationally wrongful acts, circumstances precluding wrongfulness, bilateral investment treaties.

RÉSUMÉ: Cet article a pour objectif montrer le débat qui se développe aujourd'hui autour des causes d'exclusion de l'illicéité des faits commis par l'État dans le cadre de compromis économiques et plus précisément contribuer à la compréhension du concept d'État de nécessité. Ainsi, l'analyse juridique de l'article se construit à partir de la distinction des sources qui justifient l'invocation de l'Etat de nécessité et les effets de cette différentiation sur la charge de la preuve de la nécessité, l'intérêt essentiel de l'Etat qui se voit endommagé, le calcul de dommages et l'annulation de certaines décisions arbitrales dut à l'incorrecte application de cette cause.

Mots-clés: Le centre international pour le règlement des différends relatifs aux investissements (CIRDI), La nécessité en droit international, responsabilité de l'État pour fait internationalement illicite, circonstances excluant l'illicéité, Les traités bilatéraux d'investissement. 


\section{INTRODUCCIÓN}

Las relaciones entre normas y principios generales del derecho internacional público y sistemas más específicos y particulares de derecho, como el derecho comercial internacional o el derecho de la inversión extranjera, son cada vez más estudiadas por la doctrina, por dos principales razones: la primera, la generalidad de las normas de procedimiento que permiten la aplicación de normas generales de derecho internacional público en estos sistemas (por ejemplo, el artículo 42 del Convenio del Centro Internacional de Arreglo de Diferencias relativas a Inversiones [CIADI] ${ }^{1}$ ) y las perplejidades producto de la jurisprudencia en la materia, constantemente fragmentada y que ante la ausencia de un sistema de precedente rígido, tienda a trasegar entre diferentes soluciones para una misma pregunta de derecho. ${ }^{2}$

Una de esas relaciones interesantes y problemáticas entre normas de derecho internacional público y derecho de la inversión extranjera es la existente entre normas del derecho de la responsabilidad internacional de los Estados por hechos internacionalmente ilícitos y el derecho de la inversión extranjera en el ámbito de la solución de controversias inversionista-Estado. El presente documento pretende abordar el recurrente debate sobre las causales de exclusión de ilicitud, ampliamente desarrolladas por el derecho internacional público en la responsabilidad internacional del Estado, y su relevancia en materia de compromisos económicos regulados por el derecho de inversiones, buscando presentar un aporte al entendimiento del concepto del estado de necesidad y su aplicabilidad en el ámbito del derecho de la inversión extranjera, mediante los desarrollos del CIADI en la materia como consecuencia de los casos contra Argentina a raíz de las medidas adoptadas en la crisis económica de inicios de este siglo.

Así, este estudio, tras analizar la noción de estado de necesidad presentada por el derecho internacional público y proponer clasificaciones de sus

1 Artículo 42. El Tribunal decidirá la diferencia de acuerdo con las normas de derecho acordadas por las partes. A falta de acuerdo, el Tribunal aplicará la legislación del Estado que sea parte en la diferencia, incluyendo sus normas de derecho internacional privado, y aquellas normas de derecho internacional que pudieren ser aplicables.

2 Pellet, Alain, "The Case Law of the ICJ in Investment Arbitration”, ICSID review, 28.2, 2013, pp. 223-240. 
Esta revista forma parte del acervo de la Biblioteca Jurídica Virtual del Instituto de Investigaciones Jurídicas de la UNAM

posibles subespecies en materia de inversiones, realiza un análisis jurídico sobre la distinción de la fuente a partir de la cual se invoca el estado de necesidad (como norma consuetudinaria o como norma incorporada en un Acuerdo Bilateral de Inversiones [TBI]) y los efectos de esta diferenciación en los laudos arbitrales. Lo anterior, tanto en el ámbito sustantivo de responsabilidad internacional, como en la carga de la prueba de la necesidad y la anulación de ciertos laudos por la incorrecta aplicación de tal causal.

\author{
II. CODIFICACIÓN, ALCANCE Y NATURALEZA JURÍDICA \\ DEL ESTADO DE NECESIDAD COMO CAUSAL DE EXCLUSIÓN DE ILICITUD
}

El estado de necesidad en la actualidad se encuentra codificado como una causal de exclusión de ilicitud dentro del régimen desarrollado por la Comisión de Derecho Internacional, en su Proyecto para la Responsabilidad Internacional del Estado por Hechos Internacionalmente Ilícitos ${ }^{3}$ (el Proyecto). El estado de necesidad (también mencionado algunas veces como necesidad) ${ }^{4}$ constituye una de las causales más controversiales dentro del Proyecto, en el cual se incluyeron otras causales históricas de exclusión de ilicitud como la fuerza mayor, la legítima defensa o el peligro extremo.

De los trabajos preparatorios y de los debates al seno de la Comisión, se pueden extraer las siguientes consideraciones para dilucidar la naturaleza de la causal y su difícil relación con el régimen de inversiones, que desarrollaremos más adelante. En primer lugar, es de resaltar que la Comisión, tanto en la lectura del relator Roberto Ago como en lecturas posteriores, ${ }^{5}$ no pretendió definir todos los casos de necesidad, excluir casos concretos,

3 CDI, "Draft articles on Responsibility of States for Internationally Wrongful Acts with commentaries”, Yearbook of the International Law Commission, 2001, vol. II, 2, pp. 80-84.

4 La literatura sobre el tema ha adoptado indistintamente las expresiones "necesidad" y "estado de necesidad" parafraseando la expresión anglosajona que denomina originalmente a la causal, siendo esta: necessity. En sentido estricto, "estado de necesidad” es el nombre de la causal de exclusión de ilicitud, con todas sus subreglas, mientras que "necesidad” es uno de sus elementos: la circunstancia especial en la que uno de los intereses esenciales del Estado se ve afectado o amenazado.

5 Crawford, James, "Revising the Draft Articles on State Responsibility", European Journal of International Law, núm. 10.2,1999, pp. 435-460. 
Esta revista forma parte del acervo de la Biblioteca Jurídica Virtual del Instituto de Investigaciones Jurídicas de la UNAM

o extender una definición absoluta del concepto: el trabajo de codificación giró alrededor de establecer su existencia como causal, los límites aplicables a esta, su relación con normas que incluyeran obligaciones internacionales particulares (normas primarias) y las consecuencias derivadas de la utilización correcta o incorrecta de la misma al momento de ser invocada por un Estado, ${ }^{6}$ es decir, el Proyecto le dio a la necesidad, carácter de normas secundarias. $^{7}$

En segundo lugar, para entender las consideraciones que adelante se harán sobre la necesidad en materia de inversión, es menester saber que la codificación moderna del concepto ha buscado diferenciarlo de nociones similares del derecho internacional y de las relaciones internacionales, algunas antiguas y otras modernas, ${ }^{8}$ suscritas a corrientes tradicionales de derecho natural. ${ }^{9}$ Tal es el caso de la autopreservación del Estado, la razón o interés del Estado o la supervivencia del Estado, ${ }^{10}$ todas ellas también

6 Ago, Roberto, Addendum to the Eighth Report on State Responsibility, UN Doc. A/ CN.4/318/Add.5-7, 29 de febrero, 10 y 19 de junio de 1980, Nueva York, International Law Commission, 1980.

7 En derecho internacional público y, especialmente, en materia de responsabilidad internacional del Estado es común el uso de las categorías de "norma primaria" y "norma secundaria” las cuales inspiran la lógica del proyecto de la Comisión; norma primaria es aquella que contiene obligaciones sustantivas particulares que vinculan a Estados específicos y que se encuentran plasmadas en diversos instrumentos convencionales, mientras que norma secundaria es aquella que bajo un carácter más general, determina las consecuencias de incumplir una obligación internacional, los criterios de atribución de tal incumplimiento, las causales de exclusión de ilicitud frente a ese incumplimiento, entre otros elementos de carácter procedimental relativos a la responsabilidad internacional. Véase Gourgourinis, Anastasios, "General/Particular International Law and Primary/Secondary Rules: Unitary Terminology of a Fragmented System”, European Journal of International Law, núm. 22.4, 2011, pp. 993-1026.

8 El estado de necesidad, tampoco debe ser confundido con el concepto de derecho internacional humanitario conocido como "necesidad militar", conexo al principio de distinción y al principio proporcionalidad del DIH y aplicable a las acciones militares dentro de conflictos armados.

9 Magenis, Sean D., "Natural Law as the Customary International Law of Self-Defense", Boston University International Law Journal, 20, 2002, p. 413.

10 Las nociones citadas se sitúan en los puntos de contacto entre teorías realistas de las relaciones internacionales y el derecho internacional clásico: concepciones como "razón de Estado" o "supervivencia del Estado" parten de la noción realista de "interés nacional" (Morgenthau) como máxima medida de la validez del actuar del Estado, siendo tal interés o razón el conjunto de sus motivaciones en materia de política exterior y soberanía interna, que determinan su actuación en el sistema internacional y especialmente, su comportamiento 
Esta revista forma parte del acervo de la Biblioteca Jurídica Virtual del Instituto de Investigaciones Jurídicas de la UNAM

prósperas en las teorías realistas de las relaciones internacionales. Aquellas nociones del derecho internacional clásico aparentaban facultar al Estado a actuar de forma extralegal, en tanto exigían la derogación de cualquier otro derecho u obligación que les fuese opuesto.

En cambio, desde el entendimiento de la Comisión y de la codificación moderna, el estado de necesidad se presenta como una causal de exclusión de ilicitud, cuya presencia no deroga las obligaciones que pretende apenas suspender, ni la responsabilidad. Se relaciona con la idea de una aplicación justa y ponderable de las obligaciones internacionales, que faculta al Estado para actuar desatendiendo una obligación internacional en momentos de crisis, para luego reivindicarla una vez restablecido el orden, sugiriendo que las obligaciones contraídas no deben ser entendidas como pétreas. ${ }^{11}$

La codificación resultante del trabajo de la Comisión es, en primer lugar, de redacción negativa, "la necesidad no se puede invocar salvo que..." y, en segundo lugar, restringida a expresar los límites de la misma en caso de ser invocada por un Estado:

Artículo 25

Estado de necesidad

1. Ningún Estado puede invocar el estado de necesidad como causa de exclusión de la ilicitud de un hecho que no esté de conformidad con una obligación internacional de ese Estado a menos que ese hecho:

a) Sea el único modo para el Estado de salvaguardar un interés esencial contra un peligro grave a inminente; y b) No afecte gravemente a un interés esencial del Estado o de los Estados con relación a los cuales existe la obligación, o de la comunidad internacional en su conjunto.

2. En todo caso, ningún Estado puede invocar el estado de necesidad como causa de exclusión de la ilicitud si: a) La obligación internacional de que se trate

frente a sus obligaciones, incluso permitiendo la derogación o incumplimiento de las mismas para garantizar la estabilidad estatal y la preservación de sus intereses. Para un estudio sobre la razón de Estado y su rol en el comportamiento de los sujetos de derecho internacional en las relaciones internacionales, véase Colacrai, Miryam, "El legado hobbesiano acerca del «estado de naturaleza» en los estudios de relaciones internacionales de Hans Morgenthau y Raymond Aron. Matices y diferencias”, Revista de Historia Actual, núm.1, 2010, pp. 97-105.

11 Heathcote, Sarah, "State of Necessity", Oxford Bibliographies Online: International Law, documento electrónico, disponible en: http://www.oxfordbibliographies.com/view/document/ obo- 9780199796953/obo-9780199796953-0025.xml. 
excluye la posibilidad de invocar el estado de necesidad; o b) El Estado ha contribuido a que se produzca el estado de necesidad. ${ }^{12}$

En relación con el Estado que pretende invocar esta causal, son elementos determinantes: 1) la definición de un interés esencial que sea determinado y que se encuentre en peligro; 2) que la importancia de tal interés para el Estado sea tan determinante que lo lleve a optar por dejar de cumplir con una obligación considerada de menor importancia para salvaguardar el mismo, y 3) que exista un peligro inminente y cierto, que amenace tal interés esencial. Todo lo anterior bajo la condición de que el Estado no haya contribuido en la consolidación de tal peligro.

Si bien se ha procurado dotar de contenido a la causal de estado de necesidad mediante el concepto de "interés esencial", es también necesario observar que este último, es en sí mismo de difícil definición. Lo anterior ha sido claramente evidenciado en el trabajo de la Comisión, la cual ha observado que bajo el título de "estado de necesidad", tanto antes como después de su codificación, se han formulado reclamaciones de todo tipo, involucrando la noción de "interés esencial" en términos de territorio, de población, de recursos económicos, de recursos militares e incluso de especies animales. Igualmente, la literatura de la Comisión de Derecho Internacional incluye una gran cantidad de casos en los que se discute si su utilización hace referencia al artículo 25 o a casos que corresponden realmente a la legítima defensa, fuerza mayor o peligro extremo. ${ }^{13}$

En cuanto a la naturaleza jurídica del estado de necesidad, la Comisión desde muy temprano estableció su existencia como norma consuetudinaria de contenido general, ${ }^{14}$ especialmente en cuanto a la forma de ser aplicada como causal de exclusión y a los casos en donde no es aplicable (prohibición expresa de un tratado, contribución del Estado a la crisis, afectación de nor-

12 CDI, "Draft articles on Responsibility of States for Internationally Wrongful Acts with commentaries", Yearbook of the International Law Commission, 2001, vol. II, 2, pp. 80-84.

13 Arévalo, Walter, "Responsabilidad internacional del Estado por hechos internacionalmente ilícitos: las causales de exclusión de Ilicitud, su contenido y escenarios de aplicación”, en Derecho internacional: varias visiones un maestro. Liber amicorum en Homenaje a Marco Gerardo Monroy Cabra, Universidad Colegio Mayor de Nuestra Señora del Rosario, 2015, pp.30-54.

14 Goldsmith, Jack L. y Posner, Eric, “A Theory of Customary International Law”, The University of Chicago Law Review, 1999, pp. 1113-1177. 
Esta revista forma parte del acervo de la Biblioteca Jurídica Virtual del Instituto de Investigaciones Jurídicas de la UNAM

mas de Ius Cogens) ${ }^{15}$ El estado de necesidad, como norma consuetudinaria, puede convertirse en norma positiva en distintos tratados, lo cual implica que puede limitar o ampliar las materias en que se aplica. ${ }^{16} \mathrm{Ya}$ en los trabajos preparatorios de la Comisión se estudiaban $\operatorname{casos}^{17}$ en los que la causal había sido utilizada para desatender obligaciones de carácter monetario con sujetos protegidos por regímenes históricos de inversiones. ${ }^{18}$

Al estudiar fallos de alta trascendencia internacional, puede observarse cómo la existencia y naturaleza del estado de necesidad quedó confirmada en el Caso Gabcikovo-Nagymaros, ${ }^{19}$ en el cual la Corte Internacional de Justicia reconoció la viabilidad de la necesidad como justificación temporal para el incumplimiento de obligaciones internacionales y como norma consuetudinaria, ${ }^{20} \sin$ limitar con ello sus ámbitos materiales de aplicación, pero reconociendo los mismos contornos y límites, ${ }^{21}$ posteriormente plasmados en la versión final del Proyecto de la Comisión de Derecho Internacional.

Las posturas frente a la pluralidad de ámbitos en donde se puede presentar la necesidad como defensa, se debaten entre, por un lado, las que consideran a la necesidad como una norma consuetudinaria per se, indefinida en cuanto al contenido material y aplicable a cualquier temática, siempre que se presenten los elementos anteriormente anotados, y por otro lado, aquellas posturas más reflexivas, que intentan identificar los ámbitos materiales donde la necesidad ha sido recientemente invocada por las partes y efecti-

15 Gómez-Robledo, Antonio, "Le ius cogens international: sa genèse, sa nature, ses fonctions”, Recueil des Cours. Académie de Droit International de La Haye, 1982, pp. 9-217.

16 Abello, Ricardo, "La costumbre como fuente de derecho internacional: Una caja imposible de cerrar", Derecho internacional: varias visiones un maestro. Liber amicorum en Homenaje a Marco Gerardo Monroy Cabra, Universidad Colegio Mayor de Nuestra Señora del Rosario, 2015, pp. 3-29.

17 Award of 29 March 1933, arbitrator O. Unden: Case of the Forests of Central Rhodope (Merits) (Bulgaria v. Greece)

18 ONU, Reports of International Arbitral Awards, vol. III, United Nations publication. Sales No. 1949.V.2, p. 1405.

19 CIJ, Case Concerning the Gabčikovo-Nagymaros Project (Hungary/Slovakia): Judgment of 25 September 1997. ICJ Reports (1997), pp. 7-84.

20 Reichert-Facilides, Daniel, "Down the Danube: The Vienna Convention on the Law of Treaties and the Case Concerning the Gabčikovo-Nagymaros Project”, International and Comparative Law Quarterly, 47.04, 1998, pp. 837-854.

21 Boyle, Alan, "The Gabčíkovo-Nagymaros Case: New Law in Old Bottles”, Yearbook of International Environmental Law, 8.1,1998, pp. 13-20. 
Esta revista forma parte del acervo de la Biblioteca Jurídica Virtual del Instituto de Investigaciones Jurídicas de la UNAM

vamente considerada por los tribunales, y distinguir dentro de ellos, cuáles son verdaderos casos de necesidad y cuáles son sólo excesos en el uso de la defensa y de la noción subyacente de la "protección de un interés nacional del Estado". ${ }^{22}$ Lectura esta última, generalmente producto de prácticas abusivas del Estado frente a deudas internacionale ${ }^{23}$ y que recientemente ha ganado adeptos gracias a los debatidos laudos del Centro Internacional de Arreglo de Diferencias relativas a Inversiones (CIADI) ante el caso de la crisis económica de Argentina y su relación con la protección del Estado frente a riesgos o crisis con orígenes sociopolíticos. ${ }^{24}$

Entre los usos de la defensa de necesidad frente al incumplimiento de obligaciones internacionales que han sido ampliamente criticados por la doctrina, la literatura presenta como ejemplos, la construcción de un muro en Palestina y los usos de la fuerza que no atienden todos los criterios del Sistema de Naciones Unidas, ${ }^{25}$ las acciones en Tanzania o Macedonia en contra del non-refoulement, ${ }^{26}$ que en ocasiones pretendieron devolver al país de origen o cerrar sus fronteras a refugiados bajo argumentos de necesidad estatal, ${ }^{27}$ la tenencia de armas nucleares aun en presencia de obligaciones de desarme, las medidas soberanistas, proteccionistas arbitrarias frente a obligaciones financieras internacionales firmadas previamente al acaecimiento de crisis económicas, o el pretendido cierre del espacio Schengen en casos de alzamientos políticos en países árabes vecinos del mediterráneo. ${ }^{28}$

22 Sloane, Robert D., "On the Use and Abuse of Necessity in the Law of State Responsibility”, American Journal of International Law, 106.3, 2012, pp. 447-508.

23 Mancina, Emily F., "Sinners in the Hands of an Angry God: Resurrecting the Odious Debt Doctrine in International Law”, George Washington International Law Review, núm. 36, 2004, p. 1239

24 Ginsburg, Robert, "Political Risk Insurance and Bilateral Investment Treaties: Making the Connection", The Journal of World Investment \& Trade, 14.6, 2013, pp. 943-977.

25 Laursen, Andreas, “The Use of Force and (the State of) Necessity”, Vanderbilt Journal of Transnational Law, 37, 2004, pp. 485.

26 Lauterpacht, Elihu y Bethlehem, Daniel, "The Scope and Content of the Principle of Nonrefoulement: Opinion”, Refugee Protection in International law: UNHCR's Global Consultations on International Protection, 2003.

27 Boed, Roman, "State of Necessity as a Justification for Internationally Wrongful Conduct", Yale Hum. Rts. \& Dev. LJ, 3, 2000, p. 1.

28 Sloane, Robert D., "On the Use and Abuse of Necessity in the Law of State Responsibility”, American Journal of International Law, 106.3, 2012, p. 449. 
Esta revista forma parte del acervo de la Biblioteca Jurídica Virtual del Instituto de Investigaciones Jurídicas de la UNAM

En atención a que la codificación de la necesidad por parte de la Comisión se da sólo mediante normas secundarias, y no a partir de una limitación expresa de su ámbito material, como sí lo hizo en otras causales (peligro extremo), consideramos que la causal de exclusión y norma consuetudinaria del "estado de necesidad", admite múltiples tópicos siempre que se den los elementos del artículo 25 del Proyecto. En tal sentido, partiendo de la existencia de diferentes casos en los cuales los Estados pueden justificar un estado de necesidad, en este escrito nos centraremos en el análisis de una clase de necesidad de interés especial en el régimen del derecho internacional económico: el estado de necesidad económico o financiero.

Con el propósito de avanzar en el estudio propuesto, en primer lugar presentaremos una serie de consideraciones en cuanto a la existencia y diferentes tipos de estado de necesidad económico, enseguida haremos un análisis de su utilización en el CIADI y de las controversiales aproximaciones en relación con la eficacia de su invocación a través de distintos laudos arbitrales que se han venido convirtiendo en el estado del arte, discusión recurrente y jurisprudence constante $e^{29}$ en la materia, para a partir de este marco desarrollar una serie de consideraciones sobre las consecuencias procedimentales de la invocación de la necesidad, dependiendo de cómo se le entienda en cuanto al tipo de norma que puede llegar a ser (consuetudinaria o convencional).

\section{LA EXISTENCIA DEL ESTADO DE NECESIDAD EN MATERIA ECONÓMICA}

Para abordar el análisis de la aplicación de la causal de estado de necesidad en el arbitraje de inversión, es importante comenzar por definir los contornos del tipo de "necesidad" que llamaremos estado de necesidad económico y/o financiero, porque es precisamente en esta hipótesis en la cual se encuentran la mayor cantidad de violaciones posibles al régimen de inversiones e igualmente, la que a pesar de haber sido ya analizada en el CIADI en varios laudos, aún no ha sido definida jurídicamente de forma plena y final en ese ámbito institucional.

29 Guillaume, Gilbert, “The Use of Precedent by International Judges and Arbitrators”, Journal of International Dispute Settlement, 2.1, 2011, pp. 5-23. 
Esta revista forma parte del acervo de la Biblioteca Jurídica Virtual del Instituto de Investigaciones Jurídicas de la UNAM

La respuesta frente a la búsqueda del contenido de este concepto se puede abordar desde varias ópticas, dependiendo de dónde se ubique el énfasis relativo a los asuntos económicos relacionados con la causal de exclusión.

\section{Estado de necesidad en materia económica desde el punto de vista de la obligación violada}

Éste se refiere a la calificación temática de la obligación que se ve incumplida (el tema objeto del tratado, ${ }^{30}$ que en esta categoría, debe ser económico) y a la cual se le aplica la doctrina de la necesidad en el marco de un concepto amplio que abarca todo "interés esencial del Estado". Así, entonces, lo económico es la obligación incumplida, mientras que las fuentes de la necesidad, como el interés esencial del Estado pueden ser relativas a otros temas no económicos.

Es decir, en los términos del Proyecto de la Comisión, ${ }^{31}$ en esta categoría, la necesidad puede ser invocada para salvaguardad intereses humanitarios, ambientales, relativos a seguridad y defensa militar del Estado, salubridad, integridad territorial etcétera, ${ }^{32}$ de manera que le permitan al Estado tomar la decisión de "incumplir" una obligación de orden económico, como repudiar una deuda o violar un régimen o tratado bilateral de protección de inversiones (TBI). ${ }^{33}$ En tal caso, lo "económico" de la necesidad planteada, no sería su causa, que puede fundamentarse en cualquier temática, sino la materia y naturaleza de la obligación incumplida, que es claramente económica.

Desde la codificación de la Comisión, este caso es posible en la medida que el artículo 25 del Proyecto no delimita los temas que pueden llevar a un Estado a declarar el estado de necesidad, como tampoco el tipo de obli-

30 “Objeto" entendido como tema o asunto, pero también propósito central del Tratado, a la luz de los artículos 2,18,19,20,23,31,40,41,58,61 de la Convención de Viena sobre el Derecho de los Tratados, U.N. Doc A/CONF.39/27 (1969).

31 CDI, "Draft articles on Responsibility of States for Internationally Wrongful Acts with commentaries", Yearbook of the International Law Commission, 2001, vol. II, 2, pp. 80-84.

32 Laursen, Andreas, "Use of Force and (the State of) Necessity", Vanderbilt Journal of Transnational Law, núm.37,2004, p. 485.

33 Downs, George W. y Jones, Michael, "Reputation, Compliance, and International Law", The Journal of Legal Studies, 31.S1, 2002, pp. 95-114. 
Esta revista forma parte del acervo de la Biblioteca Jurídica Virtual del Instituto de Investigaciones Jurídicas de la UNAM

gaciones que con él se pueden excluir de ilicitud al ser incumplidas (salvo el Ius Cogens, lo que es un asunto no de limitación temática, sino de jerarquía normativa). ${ }^{34}$

2. Estado de necesidad económico desde la perspectiva de la causa económica del incumplimiento

Éste hace referencia directamente a un problema de naturaleza económica, una quiebra, un default, una crisis monetaria que afecta gravemente un interés esencial del Estado, también de orden económico (estabilidad económica, soberanía monetaria), que lo mueve a tomar medidas que terminan pretermitiendo o violando una obligación de naturaleza económica, financiera y/o que sea parte de un régimen bilateral de inversión. ${ }^{35}$

La historia de la codificación del Estado de necesidad como norma consuetudinaria no es ajena a este tipo específico de necesidad económica y de su uso en diversas jurisdicciones. En tal sentido, el escenario de la protección al inversionista no es necesariamente el único ámbito del derecho económico internacional donde se han presentado defensas equivalentes. Los Anuarios de la Comisión relativos a la elaboración del Proyecto, dan cuenta de laudos históricos aceptando o analizando la defensa, tanto en lo que hemos denominado de "necesidad en materia económica desde el punto de vista de la obligación económica violada", como también "desde la perspectiva de la causa económica del incumplimiento":

- El caso de las indemnizaciones a Rusia (Russian Indemnities case, 1912) debidas por Turquía con ocasión de los daños causados a ciudadanos rusos en la guerra de 1877, la Corte Permanente de Arbitraje acepta la existencia de la posibilidad de excluir la ilicitud por la demora de un pago de indemnizaciones por parte de Turquía (Imperio Otomano), quien invoca una crisis económica, reconociendo con ello la existencia del estado de necesidad y distinguiéndolo de la fuerza mayor. No obstan-

34 Shelton, Dinah, "Normative Hierarchy in International Law", American Journal of International Law, 2006, pp. 291-323.

35 Cortes Marin, J. M., "El estado de necesidad en materia económica y financiera”, Anuario Español de Derecho Internacional, núm. XXV, 2009, pp. 119-173 
te, la Corte termina negando la razón a Turquía, por no probar que la magnitud de la crisis le imposibilitaba realizar el debido pago o que hacerlo afectaba un interés esencial del Estado:

Es indiscutible... que Turquía se encontraba, desde 1881 hasta 1902 , en medio de dificultades financieras de la mayor seriedad, combinado con los eventos nacionales y extranjeros insurrecciones, guerras) que obligaron a hacer una especial disposición de una gran parte de sus ingresos, a entregar al control extranjero una parte de sus finanzas, incluso a conceder una demora de pagos al Banco otomano, y, en general, a retrasar el pago de sus obligaciones a través de aplazamientos... Pero por otra parte, es claro que durante este mismo período, y especialmente después de la creación del Banco Otomano, Turquía fue capaz de obtener algunos préstamos a tasas favorables, para redimir otros préstamos, y, para pagar una gran parte de su deuda pública, estimada en 350 millones de francos. Sería claramente exagerado considerar que el pago (o la obtención de un préstamo para el pago) de la relativamente pequeña suma de cerca de seis millones de francos debidos a los reclamantes rusos constituya entonces un peligro para la existencia del Imperio Otomano o comprometer seriamente su situación interna o externa. La excepción no puede, por lo tanto, aceptarse. ${ }^{36}$

- La literatura sobre la historia de la necesidad también nos presenta el Caso Société Commerciale De Belgique, ante la extinta Corte Permanente Internacional de Justicia. En el caso, se debate la responsabilidad internacional del Estado cuando Grecia decide no pagar sus deudas, ya confirmadas por laudos arbitrales, adquiridas ante un sujeto de derecho privado belga, argumentando una prolongada crisis económica producto de la crisis mundial de $1929 .{ }^{37}$ El caso es de interés porque el tribunal no encuentra por parte de Grecia elementos necesarios para probar que le es imposible pagar su deuda, pero reconoce que ambos Estados concuerdan en el reconocimiento de la excusa de la necesidad económica como existente, consuetudinaria y distinguible de la fuerza mayor $;^{38}$ a

36 Traducción libre de: CPIJ, Russian Claim for Interest on Indeminities: Award Russian Claim for Interest on Indeminities Russia v. Turkey. Award Of The Tribunal, 11 de noviembre de 1912.

37 CPIJ, Caso Société Commerciale De Belgique, 1939. (ser.A/B) No. 78, 15 de junio de 1939.

38 Sloane, Robert D., "On the Use and Abuse of Necessity in the Law of State Responsibility”, American Journal of International Law 106.3, 2012, pp. 447-508. 
Esta revista forma parte del acervo de la Biblioteca Jurídica Virtual del Instituto de Investigaciones Jurídicas de la UNAM

su vez, el caso involucra la protección diplomática estatal de un sujeto de derecho privado (fuente histórica de la protección del inversionista).

Los casos presentados confirman que la necesidad se ha aplicado como defensa en el incumplimiento de obligaciones económicas adquiridas directamente con Estados o aquellas que involucran sujetos extranjeros de derecho privado. Los controversiales laudos sobre el caso de la crisis financiera argentina corresponderían a esta categoría ${ }^{39}$ y son esas decisiones las que motivan varias de las preguntas de las que nos ocuparemos más adelante.

En los casos argentinos ante el CIADI, es precisamente una crisis de orden monetario la que justifica la invocación del estado de necesidad, por el cual el Estado toma medidas de alcance económico (pesificación de la economía, restricción al retiro y la libre disposición de recursos en cuentas bancarias, bloqueo de transferencias al exterior ${ }^{40}$ ) que terminan, precisamente, violando una obligación de naturaleza económica (violación a diferentes protecciones y tratos concedidos a inversionistas en el marco de un tratado bilateral de inversión [TBI]), pero que considera amparadas por la causal de exclusión de ilicitud del Estado de necesidad. ${ }^{41}$

Este tipo de necesidad, desde toda perspectiva económica, tanto en sus causas, como en las acciones del Estado (medidas económicas) u omisiones (repudio de deudas, incumplimiento de pagos) violatorias de obligaciones internacionales, como también en la naturaleza económica de las obligaciones incumplidas (régimen bilateral de inversión), puede estar amparada en alguna de las siguientes fuentes de la causal de exclusión de ilicitud:

1) el estado de necesidad, como norma consuetudinaria y parte del derecho internacional general, ${ }^{42} \mathrm{O}$

39 Kasenetz, Eric David, "Desperate Times Call for Desperate Measures: The Aftermath of Argentina's State of Necessity and the Current Fight in the ICSID”, GeorgeWashington International Law Review, núm. 41, 2009, pp. 709.

40 Jacobs, Becky L., "Pesification and Economic Crisis in Argentina: The Moral Hazard Posed by a Politicized Supreme Court", The University of Miami Inter-American Law Review, 2003, pp. 391-434.

${ }_{41}$ Reinisch, August, Necessity in International Investment Arbitration-An Unnecessary Split of Opinions in Recent ICSID Cases-Comments on CMS v. Argentina and LG\&E v. Argentina, 2007.

42 Álvarez-Jiménez, Alberto, "Foreign Investment Protection and Regulatory Failures as States' Contribution to the State of Necessity under Customary International Law. A New 
Esta revista forma parte del acervo de la Biblioteca Jurídica Virtual del Instituto de Investigaciones Jurídicas de la UNAM

2) el estado de necesidad como parte de un TBI que expresamente faculte al Estado Receptor de la inversión, a invocar esta causal (como lo hace el Argentina - United States of America Bilateral Investment Treaty (1991), en adelante $A R G$-USABIT), delimitando o no la evaluación de tal necesidad, a circunstancias económicas.

\section{ARTÍ́CULO XI}

El presente Tratado no impedirá la aplicación por cualquiera de las Partes de las medidas necesarias para el mantenimiento del orden público, el cumplimiento de sus obligaciones para el mantenimiento o la restauración de la paz o seguridad internacionales, o la protección de sus propios intereses esenciales de seguridad. ${ }^{43}$

\section{3. ¿Puede un tratado bilateral de inversión limitar}

o prohibir la invocación de cierto tipo de estado de necesidad?

Como el artículo 25 del Proyecto no impone límites temáticos a la naturaleza de la necesidad, la invocación de la defensa del estado de necesidad ante un tratado bilateral de inversión, sólo podría limitarse temáticamente mediante una norma convencional pactada y expresamente plasmada, por ejemplo, en el tratado bilateral de inversión en cuestión, que delimite los tipos de necesidad que podrían invocarse y los que no, frente al incumplimiento de las obligaciones de ese régimen de protección al inversionista.

En ese caso, el tratado bilateral de inversión delimitaría el ámbito material de la necesidad (por ejemplo, expresando: "Ante la obligatoriedad de este TBI sólo se podrá invocar el estado de necesidad por crisis ambientales”) y la norma consuetudinaria codificada en el Proyecto, continuaría regulando los elementos "propios de norma secundaria" de la necesidad, como los casos en los que se invalida la causal por la contribución del Estado o la violación de normas de Ius Cogens (Parágrafos 2, b y 1, b, artículo 25 del Proyecto).

La posibilidad de que un tratado limite o incluso prohíba la invocación de necesidad, independiente del tema de su fuente, está implícita en el

Approach Based on the Complexity of Argentina's 2001 Crisis", Journal of International Arbitration, 27.2, 2010, pp. 141-177.

43 Tratado entre la República Argentina y los Estados Unidos de América sobre Promoción y Protección Recíproca de Inversiones, 1991 (texto auténtico), artículo XI. 
Esta revista forma parte del acervo de la Biblioteca Jurídica Virtual del Instituto de Investigaciones Jurídicas de la UNAM

parágrafo 2,a del artículo 25 del Proyecto. ${ }^{44}$ Teniendo entonces claridad sobre las posibles fuentes jurídicas de la causal del estado de necesidad, de sus formas de invocación, sus implicaciones y límites, podemos abordar el estudio concreto del estado de necesidad desde la perspectiva del CIADI.

\section{EL ESTADO DE NECESIDAD COMO DEFENSA DEL ESTADO EN MATERIA DE INVERSIÓN: SU CONTROVERSIAL USO EN EL CIADI}

Con el propósito de avanzar en el estudio de la aplicación del estado de necesidad en el ámbito económico internacional, a continuación estudiaremos algunos casos emblemáticos llevados ante el CIADI, de manera que se puedan identificar los usos y alcances invocados y reconocidos recientemente en esta instancia, las controversias en las diferentes interpretaciones de la necesidad en laudos aparentemente contradictorios ${ }^{45} \mathrm{y}$ los posibles aportes de los mismos al desarrollo del régimen de la necesidad. Posteriormente, extraeremos de ellos algunas implicaciones frente al procedimiento ante el CIADI, producto de entender y aplicar la necesidad, como norma consuetudinaria o como norma convencional parte del tratado de inversión.

La defensa del estado de necesidad ha sido recientemente invocada de forma sistemática por Argentina en los arbitrajes y respectivos procedimientos de anulación en los casos Continental, ${ }^{46} L G \& E,{ }^{47}$ Enron, ${ }^{48}$ Sempra ${ }^{49}$ y

${ }_{44}$ No todos los elementos de contenido secundario limitantes a la aplicación de la necesidad, que son norma consuetudinaria, podrían ser "modificados" mediante estipulaciones expresas en un tratado bilateral de inversión: consideramos que es posible que un tratado expresamente anule la prohibición consuetudinaria de no aceptar la necesidad cuando el Estado ha contribuido a la consolidación de la amenaza, pero no es posible que un tratado bilateral de inversión elimine la prohibición de usar la necesidad para violar normas de Ius Cogens (véase artículo 25.26,40,41 del Proyecto).

45 Waibel, Michael, "Two Worlds of Necessity in ICSID Arbitration: CMS and LG\&E", Leiden Journal of International Law, 20.03, 2007, pp. 637-648.

46 Continental Casualty Company v. The Argentine Republic, ICSID Case No. ARB/03/9, 2008.

47 LG\&E Energy Corp., LG\&E Capital Corp., LG\&E International, Inc. v. República Argentina, Caso ICSID no. ARB/02/1. 2006.

48 Enron Corporation y Ponderosa Assets, L.P. c. República Argentina, Caso ICSID no. ARB/01/3, 2007.

49 Sempra Energy International c. República Argentina, Caso ICSID no. ARB/02/16, 2007. 
Esta revista forma parte del acervo de la Biblioteca Jurídica Virtual del Instituto de Investigaciones Jurídicas de la UNAM

$C M S,{ }^{50}$ circunstancia que ha revivido el uso y la doctrina relativos a la necesidad, como también, interesantes interpretaciones de los tribunales, en ocasiones contradictorias, a favor o en contra de la defensa y sus alcances.

La posición argentina, reseñada de forma general, consistió en defenderse de las demandas de distintos consorcios y grupos inversionistas asociados a negocios y licitaciones en temas energéticos y de transporte protegidos por regímenes bilaterales de inversión, argumentando que las medidas que había tomado se justificaban como respuesta a la crisis financiera que sufría desde el año $2000,{ }^{51}$ la cual constituía un estado de necesidad en materia económica, amparado por el derecho internacional consuetudinario y en las normas del TBI con Estados Unidos. De tal manera que, a juicio del Estado argentino, si bien sus medidas afectaban, suspendían o modificaban las protecciones a estos inversionistas en materias como la convertibilidad pesodólar, la disponibilidad de divisas, el otorgamiento de licencias de servicios y los ajustes especiales de tarifas al productor según el índice de Estados Unidos, estas eran necesarias para conjurar la crisis económica del momento.

Por su parte, los demandantes, en su mayoría multinacionales que habían invertido en el país tras las atractivas privatizaciones de los sectores de obras públicas, infraestructura y servicios públicos durante los años noventa, consideraban que las medidas de emergencia se habían concentrado contra los extranjeros de forma indebida, y violaban las protecciones sustantivas de los tratados bilaterales de inversión que incluían el deber de indemnizar toda expropiación, el trato justo y equitativo, especialmente frente al derecho a no soportar cargas públicas indebidamente impuestas, las normas sobre repatriación de capitales y el trato nacional..$^{52}$

Así, las medidas adoptadas dentro de la Ley 25.561 del 6 de enero de 2002, Ley de Emergencia Pública y de Reforma del Régimen Cambiario,53

50 CMS Gas-Transmission Company c. República Argentina, Caso ICSID, n ARB/01/8. 2005.

51 Di Rosa, Paolo, “The Recent Wave of Arbitrations Against Argentina Under Bilateral Investment Treaties: Background and Principal Legal Issues”, The University of Miami InterAmerican Law Review, 2004, pp. 41-74.

52 Ibidem, pp. 42-44.

53 Ley 25.561 República Argentina. Emergencia Pública y Reforma Del Régimen Cambiario: "Declárase la emergencia pública en materia social, económica, administrativa, financiera y cambiaria. Régimen cambiario. Modificaciones a la Ley de Convertibilidad. Reestructuración de las obligaciones afectadas por el régimen de la presente ley. Obligaciones vinculadas al sistema financiero. Obligaciones originadas en los contratos de la administración regidos 
Esta revista forma parte del acervo de la Biblioteca Jurídica Virtual del Instituto de Investigaciones Jurídicas de la UNAM

estaban asociadas a una causal de exclusión de ilicitud, como a las medidas de poder de policía y otras facultadas reservadas al Estado dentro delTBI, ${ }^{54}$ por lo que no constituían actos violatorios del régimen bilateral de inversión.

\section{LA EXPERIENCIA EN LOS LAUDOS DEL CIADI PARA LA CRISIS ARGENTINA: LECCIONES SOBRE LA APLICACIÓN DE LA DEFENSA DE LA NECESIDAD EN EL ARBITRAJE BILATERAL DE INVERSIÓN}

Es necesario comenzar recapitulando los aspectos generales de los desenlaces de los casos en cuestión y la relevancia del estado de necesidad en los mismos: en los casos LG\&E y Continental la defensa de la necesidad (como causal de exclusión de ilicitud) fue aceptada en sede del tribunal; en los casos Enron, Sempra y CMS el estado de necesidad como defensa fue rechazado en distintos grados por el tribunal en cada caso concreto. La posibilidad, en sentido general, de que la causal de exclusión de ilicitud por estado de necesidad sea invocada por un Estado, fue reconocida, en sede de anulación promovida por Argentina en aplicación del artículo 52 del Convenio del CIADI.

Particularmente, los laudos de Enron y Sempra fueron anulados por inaplicación del derecho, precisamente, por haber rechazado la defensa de la necesidad por una argumentación defectuosa en el análisis de sus requisitos de invocación contenidos en las normas del Proyecto de la Comisión de Derecho Internacional. ${ }^{55}$

En los casos anteriores, el debate sobre la aplicabilidad y modo de invocación del estado de necesidad gira alrededor de la relación entre el artí-

por normas de derecho público. Obligaciones originadas en los contratos entre particulares, no vinculadas al sistema financiero. Canje de títulos. Protección de usuarios y consumidores. Disposiciones complementarias y transitorias".

Sancionada: Enero 6 de 2002.

54 Sommer, Christian G., "La aplicación de estándares de protección de inversiones extranjeras. Una mirada desde los casos argentinos", Anuario Colombiano de Derecho InternacionalACDI, núm. 6, 2013, pp. 95-130.

55 Wald, Arnoldo, "Estado de necesidad en Enron, Sempra y CMS: extralimitación manifiesta de las facultades como causal de anulación", Anuario Latinoamericano de Arbitraje, "Sistema de Anulación de los Laudos CIADI", núm.1, 2011. 
Esta revista forma parte del acervo de la Biblioteca Jurídica Virtual del Instituto de Investigaciones Jurídicas de la UNAM

culo 25 del Proyecto (que recoge normas consuetudinarias) y el artículo XI del TBI (normas de carácter convencional), relación que amerita varias reflexiones cuando se presentan las siguientes hipótesis:

1) La posibilidad de que el tribunal aplique de forma concomitante (simultánea) ambas normas y exija al Estado el cumplimiento del conjunto de las condiciones requeridas por cada una de ellas.

2) Que el tribunal se decida por la inaplicación de uno de los dos tipos de normas, priorizando el otro, considerándolo como único test de necesidad aplicable.

A continuación, se analizará cada uno de los casos mencionados con el propósito de plantear conclusiones tanto sustantivas como procedimentales en relación con la causal y las distintas consecuencias que en estos casos ha traído su invocación.

\section{El Caso Enron: estándares de la necesidad como norma consuetudinaria y su rol en el arbitramento del CIADI}

En este caso, la demanda es presentada por inversionistas extranjeros del sector de transportadores de gas, que argumentaban la violación de normas sustantivas del TBI Argentina-Estados Unidos relativas al trato justo y equitativo y a la cláusula paraguas. ${ }^{56}$ Según los inversionistas, estas protecciones fueron vulneradas por las medidas argentinas de emergencia en lo relativo al cálculo de tarifas en dólares y a las restricciones a su potestad de modificar las tarifas dependiendo del ajuste del índice de precios al productor. Argentina presentó una defensa de necesidad que algunos autores han de-

56 Artículo II(2)(C, Tratado entre la República Argentina y los Estados Unidos de América sobre Promoción y Protección Recíproca de Inversiones, Adoptado el 14 de noviembre de 1991 en Washington D.C.

Entrada en vigor el 20 de octubre de 1994: “c) Cada Parte cumplirá los compromisos que hubiera contraído con respecto a las inversiones”. La anterior disposición se considera una cláusula paraguas o una disposición de protección general pues obliga de manera amplia al Estado a cumplir con todas aquellas obligaciones que hubiese contraído con el inversionista, incluyendo derechos concedidos fuera de las protecciones establecidas en este. 
Esta revista forma parte del acervo de la Biblioteca Jurídica Virtual del Instituto de Investigaciones Jurídicas de la UNAM

nominado concomitante, ${ }^{57}$ es decir, solicitando simultáneamente la aplicación de la norma consuetudinaria (artículo 25 del Proyecto) y del artículo XI del TBI como inseparables.

El laudo del tribunal rechaza la defensa de necesidad y condena a Argentina al pago de una multimillonaria suma por los perjuicios derivados de la violación del TBI, tras no lograr probar los elementos consuetudinarios de la necesidad, pero, posteriormente, esta decisión fue objeto de anulación, medida cuya argumentación también analizaremos.

El Caso Enron ${ }^{58}$ es de especial interés por varias decisiones tomadas en torno a la naturaleza de la defensa del estado de necesidad. La anulación del laudo por extralimitación en este caso, no invalida necesariamente las construcciones hechas por el tribunal en relación con la necesidad, que deben ser tenidas en cuenta para casos futuros, pues de acuerdo con el artículo 52 del Convenio del CIADI y sus trabajos preparatorios, la anulación versa sobre la no aplicación de la ley mas no sobre el error en la aplicación, por lo que lo sostenido dentro del laudo, a pesar de su nulidad general por extralimitación, no ha quedado tildado como error de derecho ${ }^{59}$ y podría darse su ocurrencia en arbitrajes futuros, especialmente al tener en cuenta la característica independencia entre los paneles del CIADI y la dispersión de su "jurisprudencia".

En relación con la interpretación de la necesidad por parte del panel arbitral en este caso, se destacan las siguientes decisiones del laudo inicial: para el tribunal, Argentina no probó estado de necesidad bajo el artículo 25 del Proyecto, pues no demostró la afectación de un interés esencial del Estado relativo a su existencia.

De esto se decantan dos estándares que tendrían relevancia en el ámbito del CIADI, tanto en los paneles como en sede de anulación: al aplicar la defensa como norma consuetudinaria (singular o concomitantemente a una

57 Kurtz, Jürgen, “Adjudging the Exceptional at International Investment Law: Security, Public Order and Financial Crisis”, International and Comparative Law Quarterly, 59.02, 2010, pp. 325-371.

58 Enron Corporation y Ponderosa Assets, L.P.c. República Argentina, Caso ICSID núm. ARB/01 /3, 2007.

59 Wald, Arnoldo, "El estado de necesidad en arbitraje del CIADI", Latin Arbitration Law, núm. 1, disponible en: http://www.latinarbitrationlaw.com/el-estado-de-necesidad-en-arbitrajedel-ciadi/ (fecha de consulta: noviembre de 2014). 
norma convencional), los tribunales aplicarán el artículo 25 del Proyecto, exigiendo con ello que:

A) El Estado, quien tendría la carga de la prueba, demuestre el peligro al que está sometido el interés esencial y que las medidas aplicadas eran el único modo para protegerlo, y

B) Para este laudo, cuando la definición de lo que constituye un interés esencial no está definida plenamente por el TBI, se debe buscar en el derecho internacional público, ${ }^{60}$ en aplicación del artículo 42 del Convenio del CIADI. ${ }^{61}$

El panel arbitral en este caso realizó las siguientes interpretaciones en relación con los mencionados estándares A) y B), que luego fueron reprochadas en sede de anulación y que analizaremos en los dos siguientes puntos:

a) En cuanto al estándar A), el tribunal admitió la opinión de expertos en economía sobre la existencia de otras medidas disponibles o recomendables, para desvirtuar el requisito de que las medidas argentinas fueran el único modo posible de salvaguardar un interés esencial.

b) Respecto al estándar B), cuando el Estado invoque concomitantemente la norma consuetudinaria (artículo 25 del Proyecto) y la norma convencional (artículo XI delTBI), y esta norma convencional no defina plenamente "interés esencial del Estado", el tribunal consideró que no es necesario un estudio independiente de la norma convencional relativa a la necesidad, si ya se demostró desde el artículo 25 que el Estado no había probado la existencia de un interés esencial. ${ }^{62}$

60 Wald, Arnoldo, "Estado de necesidad en Enron, Sempra y CMS: Extralimitación manifiesta de las facultades como causal de anulación", Anuario Latinoamericano de Arbitraje, "Sistema de Anulación de los Laudos CIADI”, núm.1, 2011, p. 287.

61 Artículo 42. El Tribunal decidirá la diferencia de acuerdo con las normas de derecho acordadas por las partes. A falta de acuerdo, el Tribunal aplicará la legislación del Estado que sea parte en la diferencia, incluyendo sus normas de derecho internacional privado, y aquellas normas de derecho internacional que pudieren ser aplicables.

62 Enron Corporation y Ponderosa Assets, L.P. c. República Argentina, Caso ICSID no. ARB/01/3, 2007. 
Esta revista forma parte del acervo de la Biblioteca Jurídica Virtual del Instituto de Investigaciones Jurídicas de la UNAM

Esto precisamente ocurrió en el Caso Enron, en tanto el artículo XI del TBI menciona pero no define el interés esencial del Estado, al usar la expresión "intereses esenciales de seguridad": el panel arbitral, como ya había decidido desde el punto de vista del artículo 25 del Proyecto, que Argentina no había probado el interés esencial del Estado, decidió que se entendía que Argentina tampoco había probado los "intereses esenciales de seguridad" del artículo XI delTBI y no debía entrar a estudiar de fondo el artículo XI delTBI.

Estas dos interpretaciones de la forma de aplicar los estándares motivaron el proceso de anulación adelantado por Argentina, que invocó las causales de extralimitación, de falta de motivación y de inaplicación de la ley, incluidas en el art. 52.1 del Convenio del CIADI.

Del proceso de anulación solicitado por Argentina, y que efectivamente le fue concedido, se rescatan desarrollos adicionales: frente al punto A) si la necesidad en el proceso está regida por el artículo 25 del Proyecto, el Tribunal no puede negar la validez de la causal, bajo la norma secundaria de que la necesidad "es la única medida posible para conjurar la «crisis»", con sólo encontrar expertos que sugieran otras medidas económicas o que consideren las medidas del Estado como equivocadas en lo económico (hecho que ocurrió dentro del laudo anulado). Es decir, que más que la simple sugerencia económica de otras medidas, debe probarse en derecho que la medida del Estado no era la única posible. ${ }^{63}$ Este estándar, producto de la anulación, favorece al Estado ya que hace más difícil desvirtuar la adecuación de sus medidas. ${ }^{64}$ Según el Laudo de Anulación:

376. ...el Tribunal debe emplear la ley aplicable y debe expresar motivos suficientes para su decisión. En el presente caso, la lectura del razonamiento precipitado de los párrafos 300 y 308 a 309 del Laudo claramente sugiere que el Tribunal aceptó la opinión experta del profesor Edwards, por encima de la opinión experta del profesor Nouriel Roubini, en el sentido que la Argentina tenía otras opciones disponibles para afrontar la crisis económica. A partir de allí, sin mayor análisis, el Tribunal arribó de inmediato a la conclusión que las medidas adoptadas por la Argentina no eran el "único modo".

63 Wald, Arnoldo, "Estado de necesidad en Enron, Sempra y CMS: Extralimitación manifiesta de las facultades como causal de anulación”, cit., p. 287.

64 Wilson, Michael, "Enron v. Argentina Annulment Decision: Moving a Bishop Vertically in the Precarious ICSID System, The”, U. Miami Inter-Am. L. Rev, 43, 2011, pp. 347. 
377. Se le requería al Tribunal que determinara si, en función de una adecuada interpretación del Artículo 25(1)(a) de los Artículos sobre Responsabilidad del Estado, se cumplía el requisito del "único modo" de dicha disposición y no que meramente decida, desde una perspectiva económica, si había otras opciones disponibles para enfrentar la crisis económica. El Comité concluye que al determinar que las medidas adoptadas no eran el "único modo", el Tribunal de hecho no aplicó el Artículo 25(1)(a) de los Artículos sobre Responsabilidad del Estado (o más precisamente, el derecho internacional consuetudinario que dicha disposición refleja), sino que, en lugar de ello, se valió de la opinión de un perito sobre una cuestión económica. En todas las circunstancias el Comité opina que esto configura un incumplimiento en la aplicación de la ley aplicable como causal de anulación conforme al Artículo 52(1)(b) del Convenio del CIADI.

378. Asimismo, aun cuando el Tribunal de hecho estaba convencido de que no se había cumplido el requisito del "único modo" que estipula el Artículo 25(1)(a) según la evidencia con que contaba, en el razonamiento del Laudo no se advierte cómo y por qué el Tribunal arribó a dicha conclusión jurídica. Incluso si, contrario a toda apariencia, el Tribunal aplicó el requisito del "único modo" de dicho artículo, el Comité considera que el Tribunal omitió expresar los motivos de su decisión. Ello constituye causal de anulación conforme al Artículo 52(1)(e) del Convenio del CIADI.

Igualmente, para aplicar la causal como norma consuetudinaria en el Caso Enron en sede de anulación, se aplica la otra condición exigida por el Proyecto: debe quedar demostrada la no contribución del Estado al estado de necesidad para poder concederla. ${ }^{65}$

También en sede de anulación, frente al punto B) en relación con la interpretación de la concomitancia entre los artículos 25 y XI del TBI en el presente caso (y que como explicábamos anteriormente, en el laudo el tribunal decidió no aplicar lo previsto en el artículo XI delTBI, por considerar que en tanto el Estado no cumplía con las condiciones del artículo 25 del Proyecto, no era procedente un posterior estudio del artículo XI) se anuló la decisión del tribunal, a título de no aplicación de la ley:

404. En vistas de esta conclusión, en los párrafos 339 a 341 del Laudo, el Tribunal procedió a notar que como ya había determinado que la Argentina no podía apo-

65 Enron Corporation and Ponderosa Assets, L.P. v. Argentine Republic, ICSID Case no. ARB/01/3, Decision on the Application for Annulment of the Argentine Republic, 2010. 
yarse en el principio de necesidad conforme al derecho internacional consuetudinario porque no se cumplían los requisitos del Artículo 25 de los Artículos sobre Responsabilidad del Estado, por similares motivos, en este caso tampoco podía fundarse en el Artículo XI del TBI.

405. El Comité ha concluido anteriormente que, en el presente caso, se debe anular la decisión del Tribunal en cuanto a que no se habían cumplido los requisitos del Artículo 25 de los Artículos sobre Responsabilidad del Estado. Dado que esa conclusión fue la base para que el Tribunal determinara que en este caso el Artículo XI del TBI no era aplicable, el Comité entiende que esa posterior decisión del Tribunal también debe anularse.

Lo anterior, sugiere a futuro que tanto las normas del Proyecto, como las normas específicas de cada TBI sobre necesidad, deben ser aplicadas sustancialmente en los laudos, para no viciarlos de nulidad, circunstancia que estudiaremos a través del Caso Sempra y el Caso CMS.

\section{El Caso Sempra: características del peligro inminente y anulación por no aplicar normas especiales del TBI tras la aplicación de la necesidad como norma consuetudinaria}

Otro ejemplo de este debate sobre la concomitancia o especialidad de las normas relativas a necesidad, convencionales o consuetudinarias, es el Caso Sempra ${ }^{66}$ en el que inversionistas del sector energético demandan a Argentina por violación de varias protecciones sustantivas del TBI con Estados Unidos, producto del levantamiento de las protecciones relativas a la conversión y al cálculo de tarifas en dólares y otras medidas relativas a la ley de emergencia argentina.

Del caso se desprenden varias reflexiones sobre el estado de necesidad, tanto en el laudo como en la anulación. Desde el laudo, algunos desarrollos en la aplicación de la necesidad se hacen evidentes: al igual que en Enron, inicialmente el tribunal aplicando el artículo 25 del Proyecto, es decir, la necesidad como norma consuetudinaria, niega a Argentina el estado de necesidad como causal de exclusión y lo condena por violaciones al artículo II delTBI, al no probar que la existencia o supervivencia del Estado se en-

66 Sempra Energy International c. República Argentina, Caso ICSID no. ARB/02/16, 2007. 
cuentre en peligro. ${ }^{67}$ Esta posición confirma la tendencia de los tribunales arbitrales de entender "la existencia del Estado" como el verdadero "interés esencial”, ${ }^{68}$ opinión que no necesariamente es la escrita en la codificación de la costumbre desde el Proyecto, el cual no limita los intereses esenciales a la supervivencia del Estado. La igualdad entre interés esencial y supervivencia del Estado fue expuesta por el tribunal en los siguientes términos:

348. El Tribunal no tiene duda acerca de que hubo una crisis grave, y que dentro de ese contexto era poco probable que los negocios pudieran haber seguido como siempre. Sin embargo, el argumento de que dicha situación comprometió la existencia misma del Estado y su independencia, y que por ellos calificó como una situación que afectaba un interés esencial del Estado, no es convincente. Las cuestiones de orden público y malestar social podrían haberse controlado, como de hecho lo fueron, tal como se manejaron los aspectos relativos a la estabilización política de conformidad con las disposiciones constitucionales en vigor. ${ }^{69}$

Así, el laudo parece establecer tácitamente una diferencia, entre una amenaza grave a la supervivencia del Estado como interés esencial en riesgo, y del otro lado, la constante tarea de protección y estabilización política, que contrario a una emergencia, es una obligación constitucional permanente que no permite desconocer los compromisos sustantivos del TBI y no da lugar al estado de necesidad.

Dentro del litigio en el CIADI, hace carrera entonces con esta decisión, un estándar bastante exigente sobre la inminencia y gravedad del peligro al que se enfrenta el interés esencial del Estado, pues Argentina no pudo probar que la situación, por grave que fuese, no podía ser resuelta con las medidas existentes y aceptables dentro del régimen jurídico acompasado con el TBI, ${ }^{70}$ como tampoco, al igual que en el Caso Enron, que las medidas dentro de la Ley de Emergencia fuesen las únicas posibles:

67 Wald, Arnoldo. “El Estado de Necesidad en Arbitraje del CIADI." Latin Arbitration Law. 1. Consultado Noviembre 2014, disponible en: http://www.latinarbitrationlaw.com/el-estado-denecesidad-en-arbitraje-del-ciadi/.

68 Krawiec, Daniel A., "Sempra Energy International v. the Argentine Republic: Reaffirming the Rights of Foreign Investors to the Protection of ICSID Arbitration”, Law \& Bussiness Review American University, 15, 2009, pp. 311.

69 Sempra Energy International c. República Argentina, Caso ICSID no. ARB/02 / 16 , 348.2007

70 Wald, Arnoldo, "Estado de necesidad en Enron, Sempra y CMS: Extralimitación mani- 
349. Esta materia se relaciona a su vez con la supuesta existencia de un peligro grave e inminente que podría amenazar al interés esencial. Si bien el Gobierno tenía la obligación de evitar el empeoramiento de la situación, y no podía simplemente dejar que los acontecimientos siguieran su propio curso, no hay pruebas convincentes de que los acontecimientos estuvieran en efecto fuera de control y de que se hubieran tornado inmanejables.

350. Es así ciertamente evidente que debían adoptarse medidas para contrarrestar la crisis que tenía lugar, pero si acaso las medidas adoptadas en virtud de la Ley de Emergencia fueran el "único modo" para lograr este resultado, así como considerar si no había otra alternativa disponible, son cuestiones respecto de las cuales las partes y sus peritos difieren profundamente, como se indicó anteriormente. Una lamentable comparación global de experiencias en el manejo de crisis económicas demuestra que siempre hay muchos enfoques para abordar y solucionar dichos acontecimientos críticos. De ahí que sea difícil justificar el argumento de que en el caso de Argentina sólo uno de ellos era viable.

En el laudo, el Tribunal concluyó que no requería realizar un estudio de la necesidad bajo el artículo XI delTBI una vez encontrado que el caso de necesidad no cumplía con los estándares como norma consuetudinaria bajo el artículo 25 del Proyecto. Posteriormente, en el proceso de anulación adelantado por Argentina frente al laudo en el Caso Sempra, esta decisión fue catalogada por los miembros del Comité ad hoc como no aplicación del derecho $^{71}$ (error manifiesto de derecho), ${ }^{72}$ causal de anulación:

206. Por consiguiente, es necesario determinar si el error en cuestión importa (i) la no aplicación del derecho, en cuyo caso el laudo del Tribunal puede ser anulado, o (ii) la incorrecta aplicación del derecho, en cuyo caso no cabe la anulación del laudo a pesar de ser éste defectuoso en esa medida.

207. En este caso, el Comité concluye que la siguiente oración del párrafo 388 del Laudo demuestra que el Tribunal no aplicó el derecho aplicable: Como el Tri-

fiesta de las facultades como causal de anulación", Anuario Latinoamericano de Arbitraje, "Sistema de Anulación de los Laudos Ciadi”, núm.1, 2011, p. 287.

71 Sempra Energy International c. República Argentina, Caso CIADI no. ARB/02/16, (Procedimiento de anulación) 29 de junio de 2010.

72 Wald, Arnoldo, "El estado de necesidad en arbitraje del CIADI", Latin Arbitration Law, núm. 1, disponible en: http://www.latinarbitrationlaw.com/el-estado-de-necesidad-en-arbitrajedel-ciadi/, (fecha de consulta: noviembre de 2014). 
bunal ha determinado anteriormente que la crisis invocada no cumple con los requisitos del derecho consuetudinario previstos en el Artículo 25 de los Artículos sobre Responsabilidad de los Estados, debe concluir ahora que la necesidad o la emergencia no conduce en este caso a la exclusión de ilicitud, sin que haya necesidad de realizar un examen judicial adicional en virtud del Artículo XI habida cuenta que este Artículo no prevé al respecto condiciones distintas de las del derecho consuetudinario.

208. ElTribunal ha sostenido, en efecto, que los criterios sustantivos del Artículo XI simplemente no pueden aplicarse cuando las normas de derecho internacional consuetudinario — como indican los Artículos de la CDI — no conllevan a la eximición en un caso de ilicitud, y que el Artículo 25 "supera" al Artículo XI al proporcionar la norma imperativa a ser aplicada. De esta manera, el Tribunal adoptó el Artículo 25 de los Artículos de la CDI como el derecho primario a aplicarse en lugar del Artículo XI del TBI, y al hacerlo, cometió un error fundamental de identificación y aplicación del derecho aplicable.

209. El Comité, por tanto, arriba a la conclusión de que el Tribunal no ha efectuado su examen sobre la base de que la norma legal aplicable se encuentra en el Artículo XI del TBI, y que esta no aplicación constituye una extralimitación de facultades dentro del significado del Convenio del CIADI.

Esta decisión del Comité en sede de anulación ha sido controversial y ampliamente criticada ${ }^{73}$ por algunos por eximir a Argentina de las posibles violaciones al régimen de inversiones cometidas durante la crisis, pero también ha sido alabada por otros sectores de la doctrina, por aplicar preferentemente las normas en materia de necesidad del TBI y darle un valor interpretativo y complementario a las normas consuetudinarias. ${ }^{74}$

La decisión del comité de anulación se ubica al centro del debate de la relación entre norma consuetudinaria y norma convencional a propósito del estado de necesidad. Así, de la decisión podría considerarse que: 1) incluir la necesidad en el TBI como norma convencional no excluye la aplicación de las normas consuetudinarias como ayuda de interpretación o incluso, como norma necesaria para poder darle efectos al tratado; 2) pero

73 Friedland, Paul y Brumpton, Paul, "Rabid Redux: The Second Wave of Abusive ICSID Annulments”, American University International Law Review, 27.4, 2012, p. 3.

74 Von Staden, Andreas, "Towards Greater Doctrinal Clarity in Investor-State Arbitration: The CMS, Sempra, and Enron Annulment Decisions", Czech Yearbook of International Law, núm. 2, 2011 , p. 207. 
Esta revista forma parte del acervo de la Biblioteca Jurídica Virtual del Instituto de Investigaciones Jurídicas de la UNAM

de existir una norma relativa a la necesidad, que la defina plenamente o que la incluya de forma tangencial en el régimen de inversión, siempre deberá hacerse una aplicación detallada de aquel artículo, so pena de arriesgar el laudo a su anulación. La diferencia entre los efectos en la decisión del tribunal de entender la necesidad como norma consuetudinaria o aplicación del tratado, será desarrollada más adelante.

\section{El Caso CMS: la aplicación de las normas relativas}

a la necesidad estipuladas en el TBI evita la anulación del laudo

El Caso CMS, proceso motivado por hechos similares a los anteriores, que incluso después del proceso de anulación resultó a favor de los inversionistas, constituye otro de los casos centrales en el estudio de la materia y hace parte del debate contemporáneo sobre el modelo actual de anulación dentro del CIADI, ${ }^{75}$ que a raíz de las repetidas anulaciones de laudos contra el Estado, ha sido catalogado por los defensores de la protección de los inversionista como politizado o amenazante de la estabilidad ${ }^{76}$ y prestigio del arbitraje de inversiones. ${ }^{77}$

En CMS, el tribunal rechaza la defensa del estado de necesidad predicado sobre las medidas de Argentina, violatorias de las protecciones al inversionista: ${ }^{78}$ este proceso da el paso a confirmar expresamente la contribución del Estado a la consolidación de la crisis o el peligro al interés esencial del Estado, separando a Argentina de la posibilidad de invocar la necesidad como defensa desde el artículo 25 del Proyecto y el artículo XI $\operatorname{delTBI}{ }^{79}$

75 Kim, Dohyun, “Annulment Committee's Role in Multiplying Inconsistency in Icsid Arbitration: The Need to Move Away from an Annulment-Based System, The”, NYUL Rev, 86, 2011, p. 242.

76 Baldwin, Edward et al., "Limits to Enforcement of ICSID Awards", Journal of International Arbitration, 23.1, 2006, pp. 1.

77 Schreuer, Christoph, "From ICSID Annulment to Appeal Half Way Down the Slippery Slope", The Law and Practice of International Courts and Tribunals, 10 de febrero de 2011, pp. 211-225.

78 Schill, Stephan W., "From Calvo to CMS: Burying an International Law Legacy? Argentina's Currency Reform in the Face of Investment Protection: The ICSID Case CMS v. Argentina”, Transnational Dispute Management (TDM), 3.2, 2006.

79 CMS Gas-Transmission Company c. República Argentina, Caso ICSID, no. ARB/01/8. 2005. 
A nivel probatorio, en este caso, la discusión giró alrededor de la contribución del Estado a la crisis, que fue declarada al analizar la acción de diferentes gobiernos, ${ }^{80}$ en épocas distantes a la controversia, como las décadas de los ochenta y los noventa. Se demuestra el entendimiento del Estado como un todo indisoluble en materia de gobiernos y periodos de gestión pública para la prueba de la contribución a una crisis, a la cual el tribunal también le reconoce causas exógenas, pero que combinadas con los hechos, falencias y omisiones del Estado, se declara como producto, en parte, de su aporte material a la misma. ${ }^{81}$

En cuanto al precedente internacional en materia de necesidad, el laudo CMS hace uso directo de la sentencia del Caso Gabcikovo-Nagymaros ${ }^{82}$ y establece que la aplicación del artículo 25 del Proyecto debe conllevar a la elaboración de un test acumulativo, donde el tribunal sólo puede conceder la defensa de la necesidad al encontrar todos los elementos propios de la necesidad y al comprobar la ausencia de — todos — sus límites expresados en la codificación:

330. El Tribunal debe tener en cuenta otro aspecto importante. En el caso Gabcíkovo Nagymaros, la Corte Internacional de Justicia hizo referencia, de manera convincente, a la opinión de la Comisión de Derecho Internacional al efecto de que todas las condiciones que rigen el estado de necesidad deben cumplirse de una manera "acumulativa".

80 Wald, Arnoldo. "El Estado de Necesidad en Arbitraje del CIADI", Latin Arbitration Law, núm. 1, disponible en: http://www.latinarbitrationlaw.com/el-estado-de-necesidad-en-arbitrajedel-ciadi / (fecha de consulta: noviembre de 2014).

81 CMS Gas-Transmission Company c. República Argentina, Caso ICSID, no. ARB/01/8, 2005, p. 329. "El problema es entonces determinar si acaso la contribución de Argentina a la crisis ha sido lo suficientemente importante. Luego de examinar las circunstancias de la controversia, el Tribunal debe concluir que ese fue en efecto el caso. La crisis no fue generada por un gobierno en particular y reconoce sus orígenes en la crisis del decenio de 1980, agravada por las políticas gubernamentales de los años noventa, que alcanzó su punto máximo en 2002 y los años subsiguientes. De ahí que el Tribunal debe tener en cuenta que las políticas gubernamentales y sus limitaciones contribuyeron de manera importante a la crisis y la emergencia. Si bien los factores exógenos condujeron a dificultades adicionales ellas no eximen de responsabilidad al Demandado en esta materia”.

82 CIJ, Case Concerning the Gabcikovo-Nagymaros Project (Hungary/Slovakia), ICJ Reports (1997), 1997, pp. 7-84. 
Esta revista forma parte del acervo de la Biblioteca Jurídica Virtual del Instituto de Investigaciones Jurídicas de la UNAM

331. En el presente caso, como se ha concluido, hay elementos de necesidad parcialmente presentes en algunos aspectos, pero cuando se analizan los distintos elementos, condiciones y límites en su conjunto, no puede concluirse que esos elementos cumplen con la exigencia de un carácter acumulativo. Este hecho por sí mismo lleva a la conclusión inevitable de que no se han cumplido plenamente los requisitos relativos al estado de necesidad en la costumbre internacional como para permitir que se excluya la ilicitud de los actos.

En CMS, una vez agotado el estudio de la necesidad desde los elementos y límites establecidos en la codificación de la norma consuetudinaria, el tribunal realizó un estudio de la defensa de necesidad y el artículo XI del TBI, expresando que en todo caso debía ser analizado por ser una norma convencional que no podía ser considerada supletiva. Aun así, no la aplicó de forma plena pues consideró que no todas las medidas de emergencia estaban bajo el espectro del artículo XI del TBI. De esta manera, mientras los otros laudos mencionados habían decidido no aplicar el artículo XI una vez que el Estado no aprobaba el examen del artículo 25 del Proyecto, el cual entendían como máximo parámetro de aplicación de cualquier referencia a la necesidad dentro del TBI, en este caso, el tribunal acometió también el estudio de la necesidad desde el TBI.

Esta decisión de aplicación, si bien no fue completa en la medida en que el tribunal no estableció una jerarquía entre ambos regímenes o consideró a uno como lex especialis frente al otro, ${ }^{83}$ evitó la anulación del laudo por el cargo de inaplicación del derecho (esas falencias, en cuanto a no manifestar si el TBI era lex specialis y los efectos de ello, fueron consideradas como errores en la aplicación, ${ }^{84}$ que no necesariamente conllevan a la anulación en virtud del artículo 52.1b del Convenio del CIADI). ${ }^{85}$ En esta aplicación

83 Wald, Arnoldo, "El estado de necesidad en arbitraje del CIADI", Latin Arbitration Law, núm. 1, disponible en: http://www.latinarbitrationlaw.com/el-estado-de-necesidad-en-arbitrajedel-ciadi/ (fecha de consulta: noviembre de 2014).

84 Parte de la literatura, critica que los laudos de anulación permitan o validen aplicaciones incompletas o insuficientes del derecho y sólo condenen la inaplicación del mismo: Rosell, José, “The CMS Case: A Lesson for the Future?”, Journal of International Arbitration, núm. 25.4, 2008, pp. 493-502.

85 Wald, Arnoldo, "Estado de necesidad en Enron, Sempra y CMS: extralimitación manifiesta de las facultades como causal de anulación", Anuario Latinoamericano de Arbitraje, "Sistema de Anulación de los Laudos CIADI”, núm.1, 2011, p. 287. 
del artículo XI el tribunal decidió que las regulaciones económicas de Argentina no entraban en el marco de las medidas previstas para el Estado, relativas a asuntos de seguridad, negando también la defensa de la necesidad desde el ámbito convencional del TBI.

Es de resaltar, para futuras aplicaciones de la necesidad como una norma convencional o como norma consuetudinaria, que el Comité de anulación, que en este caso no anuló el laudo. En su decisión ${ }^{86}$ acepta que la concomitancia en la aplicación de las normas convencionales y consuetudinarias es algo posible.

Por otro lado, no obstante la aceptación de la concomitancia, el mismo Comité, expresamente, también admitió que, dependiendo de la redacción de la norma sobre necesidad en un TBI, se desprende la posibilidad de que la naturaleza y finalidad de la norma convencional y la norma consuetudinaria terminen por ser totalmente diferentes y que tal diferencia obligue a la subsidiariedad o inaplicación de una frente a otra. En este caso el tribunal, en lugar de asumir que la naturaleza de ambas normas es la misma por el solo hecho de que ambas regulen la necesidad, debe pronunciarse y justificar cuál norma es la aplicable o si son verdaderamente compatibles:

130. Más aún, el Artículo XI es sustancialmente distinto del Artículo 25. El primero comprende medidas necesarias para la conservación del orden público o la protección de los intereses de seguridad esenciales de cada Parte, sin calificar dichas medidas. Por su parte, el segundo supedita el estado de necesidad al cumplimiento de cuatro condiciones. Este requiere, por ejemplo, que la acción tomada "no perjudique seriamente un interés esencial del Estado o Estados respecto de los cuales existe la obligación, o de la comunidad internacional en su conjunto", requisito que es ajeno al Artículo XI. En otros términos, los requisitos contemplados en el Artículo XI no son los mismos que aquellos bajo el derecho internacional consuetudinario codificado en el Artículo 25, tal como las Partes de hecho lo reconocieron durante la audiencia ante el Comité.153 Sobre este punto, el Tribunal incurrió en un manifiesto error de derecho.

131. Teniendo ambos textos una operación y contenido diversos, el Tribunal tuvo que tomar una posición sobre su relación y decidir si ambos tenían aplicación

86 CMS Gas Transmission Company v. Argentine Republic, ICSID Case no. ARB/01/8. Annulment Proceeding, Decision Of The Ad Hoc Committee On The Application For Annulment Of The Argentine Republic. 2007. 
Esta revista forma parte del acervo de la Biblioteca Jurídica Virtual del Instituto de Investigaciones Jurídicas de la UNAM

en el presente caso. El Tribunal no entró en ese análisis, asumiendo simplemente que el Artículo XI y el Artículo 25 tienen un mismo fundamento. ${ }^{87}$

Este estudio de concomitancia es necesario considerando que desde el punto de vista de la responsabilidad internacional, existe la posibilidad de que la norma sobre necesidad estipulada en elTBI, de ser aplicada, sirva no sólo como causal eximente de ilicitud, sino como eximente de responsabilidad, pues su uso sería una aplicación del tratado mismo, una actividad facultada al Estado por las partes y no una mera causal de exclusión de ilicitud. ${ }^{88}$

Los casos $L G \& E$ y Continental nos permiten reflexionar sobre otros fenómenos de la defensa por estado de necesidad en materia de inversiones, como la carga de la prueba, tasación de daños y el uso de criterios provenientes de organizaciones internacionales ajenas al TBI para la medida de la necesidad.

\section{El Caso LG\&E: carga de la prueba sobre los inversionistas y sustracción del periodo en el que se reconoce el estado de necesidad dentro del cálculo de los daños totales}

La decisión del laudo en el Caso LG\&E suele ser identificada como la principal fuente de controversia en materia de necesidad en el ámbito del CIADI, especialmente cuando es comparada con aquellas obtenidas en los laudos anteriormente mencionados.

A diferencia de Enron, Sempra y CMS, en el Caso $L G \& E$, se reconoce por lo menos parcialmente ${ }^{89}$ (no para todas las medidas a lo largo del periodo 2000-2005) el estado de necesidad argumentado por Argentina, aplicando el artículo 25 del Proyecto, como norma guía de interpretación de los con-

87 CMS Gas Transmission Company v. Argentine Republic, ICSID Case no. ARB/01/8. Annulment Proceeding, Decision Of The Ad Hoc Committee On The Application For Annulment Of The Argentine Republic, 2007.

88 Arevalo, Walter, "Responsabilidad internacional del Estado por hechos internacionalmente ilícitos: Las causales de Exclusión de Ilicitud, su contenido y escenarios de aplicación”, Derecho internacional: varias visiones un maestro. Liber amicorum en Homenaje a Marco Gerardo Monroy Cabra, Universidad Colegio Mayor de Nuestra Señora del Rosario, 2015, pp. 30-54.

89 Falkof, Greg, "«State of Necessity» Defence Accepted in LG\&E v. Argentina ICSID Tribunal”, Transnational Dispute Management (TDM), 3.5, 2006. 
tenidos del artículo XI del TBI, que es aplicada como el derecho vigente, realizando así una aplicación concomitante de ambos criterios.

En materia procedimental, del Caso $L G \& E$ debe resaltarse que la carga de la prueba sobre los límites a la defensa de la necesidad, es localizada en la parte demandante, es decir, en los inversionistas, quienes deben probar un acto positivo del Estado para poder desvirtuar su estado de necesidad: la contribución del Estado a la crisis (parágrafos 250 a 258 del Laudo).

En tanto en el proceso la parte demandante no pudo demostrar la contribución de Argentina a la crisis y tampoco desvirtuar la adecuación de la medida, la defensa de la causal de exclusión de ilicitud por necesidad no se vio afectada por la presencia de alguno de sus límites desde el derecho consuetudinario (probar la existencia de otras medidas adecuadas o la contribución del Estado a la crisis, para desvirtuar la necesidad $)^{90}$ y por lo tanto, fue aceptada.

En el laudo CMS, anteriormente mencionado, la situación fue contraria, pues era el Estado quien debía probar una conducta de carácter negativo, es decir, probar su ausencia de contribución a la crisis, para poder acceder a la causal de exclusión de ilicitud por necesidad.

En estas circunstancias, un paquete de medidas para la recuperación económica resultó la única manera de resolver la inminente crisis. Aunque existiesen otras alternativas para desarrollar el contenido del mencionado paquete de medidas para la recuperación económica, la evidencia presentada demuestra que una solución general fue necesaria, y la regulación de las tarifas de los servicios públicos tenía que incluirse en ellas. ${ }^{91}$

La división entre estos criterios de los tribunales arbitrales continúa vigente, y en cualquier proceso futuro, la carga de la existencia de límites a la defensa de la necesidad, podría caer sobre los inversionistas.

El laudo también resulta interesante procedimentalmente en materia del cálculo de daños e indemnizaciones pues, al aplicar el artículo 25 del Proyecto como guía de interpretación del artículo XI del TBI y no como la

90 Martinez, Elizabeth, "Understanding the Debate over Necessity: Unanswered Questions and Future Implications of Annulments in the Argentine Gas Cases”, Duke J. Comp. \& Int'1 $L, 23,2012$, p. 149 .

91 LG\&E Energy Corp., LG\&E Capital Corp., and LG\&E International, Inc .v. Argentine Republic, ICSID Case no. ARB/02/1 parágrafo 257, 2006. 
fuente normativa de la causal de exclusión, la defensa de la necesidad se entiende como una aplicación misma del TBI y no como un estado de necesidad de orden consuetudinario. Como consecuencia de ello, la existencia del estado de necesidad bajo la norma del TBI se consolida como exclusión de responsabilidad y no simplemente como exclusión de ilicitud, como hubiese ordenado un régimen meramente consuetudinario, que sólo hubiera conducido a excluir el hecho ilícito pero hubiera implicado la persistencia de la indemnización por daños. ${ }^{92}$ Tal conclusión se evidencia en el siguiente apartado del laudo arbitral, en el cual todo perjuicio ocasionado durante el periodo de necesidad ${ }^{93}$ fue sustraído de los daños generales:

(4) Conclusiones del Tribunal

106. El método del Tribunal para cuantificar la indemnización calcula los dividendos que habrían percibido las Demandantes de no haber sido por los incumplimientos de Argentina y les resta aquellos dividendos que efectivamente percibieron las Demandantes. Luego, se restan las pérdidas sufridas durante el periodo del Estado de Necesidad. El método se ajustó a las observaciones de las partes sobre las deficiencias metodológicas y la verificación de las cifras de dividendos y los datos del PPI. Se agregarían los intereses compuestos a la tasa de las Letras del Tesoro de los Estados Unidos de América a seis meses. ${ }^{94}$

En conclusión, este caso demuestra que para un tribunal, dependiendo de la existencia y redacción de la norma sobre necesidad en el TBI, la invo-

92 “Artículo 27.

Consecuencias de la invocación de una circunstancia que excluye la ilicitud.

La invocación de una circunstancia que excluye la ilicitud en virtud del presente capítulo se entenderá sin perjuicio de:

a) el cumplimiento de la obligación de que se trate, en el caso y en la medida en que la circunstancia que excluye la ilicitud haya dejado de existir;

b) la cuestión de la indemnización de cualquier pérdida efectiva causada por el hecho en cuestión". Véase CDI, "Draft articles on Responsibility of States for Internationally Wrongful Acts with Commentaries", Yearbook of the International Law Commission, vol. II, 2, 2001, pp. 80-84.

93 Forji, Amin George, "Drawing the Right Lessons from ICSID Jurisprudence on the Doctrine of Necessity", Arbitration:The International Journal of Arbitration, Mediation and Dispute Management, 76.1, 2010, pp. 44-57.

94 LG\&E Energy Corp., LG\&E Capital Corp., and LG\&E International, Inc .v. Argentine Republic, ICSID Case no. ARB/02/1.2006 
cación del estado de necesidad mediante norma en un TBI, así se apoye en el derecho consuetudinario (artículo 25 del Proyecto) para interpretar la norma convencional, puede en algunos casos llevar a la exclusión de responsabilidad y no sólo de ilicitud, pues el tribunal puede interpretar que la norma convencional no es tan solo un reconocimiento de la causal de exclusión de ilicitud (que derivaría en excluir la calificación del hecho como ilícito internacional, pero no la responsabilidad por daños) sino que la norma convencional es, además, una expresa habilitación al Estado para tomar tales medidas ante determinada necesidad, sin violar el tratado y, en consecuencia, sin responsabilidad. ${ }^{95}$

\section{El Caso Continental: las normas de la OMC como medida del estado de necesidad}

El Caso Continenta $1^{96}$ presenta otros puntos de interés respecto a la consolidación de la necesidad y el régimen aplicable a ella. En Continental, el tribunal encuentra que el estado de necesidad de Argentina es admisible para algunas de sus medidas y lo aplica como norma convencional mediante el artículo XI delTBI, eximiendo de responsabilidad parcialmente al Estado y no sólo de la ilicitud, lo que hubiera sido el resultado de aplicar la necesidad como medida consuetudinaria (no todas las acciones quedaron cobijadas bajo el estado de necesidad; algunas de las demandas en materia de trato justo y equitativo fueron concedidas a los inversionistas).

Dos elementos deben ser resaltados del procedimiento en Continental: en primer lugar, el tribunal acudió a las normas y casos de la OMC para in-

95 Esto en virtud del artículo 2 del Proyecto, que sólo da pie a la responsabilidad si hay una violación de una obligación: si por el contrario, las medidas tomadas por el Estado son "cumplimiento" de una facultad otorgada al mismo, no puede haber responsabilidad. "Artículo 2.- Elementos del hecho internacionalmente ilícito del Estado

Hay hecho internacionalmente ilícito del Estado cuando un comportamiento consistente en una acción

u omisión:

a) Es atribuible al Estado según el derecho internacional; y

b) Constituye una violación de una obligación internacional del Estado". Véase CDI, "Draft articles on Responsibility of States for Internationally Wrongful Acts with commentaries", Yearbook of the International Law Commission, 2001, vol. II, 2. pp. 80-84.

96 Continental Casualty Company v. The Argentine Republic, ICSID Case no. ARB/03/9, 2008 
terpretar el alcance de la necesidad estipulada en el artículo XI del TBI y no sólo a la codificación del artículo 25 del Proyecto, por considerar algunas normas de la OMC como inspiradoras del TBI:

192. El Tribunal se enfrenta a la tarea de determinar el contenido del concepto de necesidad en el art. XI, con el fin de decidir si las diversas medidas impugnadas por el demandante fueron realmente "necesarias", como una cuestión de la causalidad. Con respecto a la prueba de la necesidad requerida para la aplicación del Convenio Bilateral, por las razones expuestas anteriormente en relación con el rol distinto de art. XI y de la defensa de necesidad en el derecho internacional consuetudinario, el Tribunal no comparte la opinión de que "el tratado de este modo se convierte en inseparable del estándar de la norma consuetudinaria en cuanto a las condiciones para la operación del estado de necesidad" como fue establecido en el caso Enron y presentado también por la parte demandante. Dado que el texto del art. XI deriva de la paralela cláusula modelo de los Tratados FCN (amistad, comercio y navegación) de EE.UU, y estos tratados a su vez reflejan la formulación de Art. XX del GATT (1947), el Tribunal considera que es más apropiado referirse a la jurisprudencia del GATT y la OMC que ha tratado ampliamente el concepto y requisitos de la necesidad en el contexto de medidas económicas que establecen excepciones a las obligaciones contenidas en el GATT, en lugar de consultar los requisitos de la necesidad bajo el internacional consuetudinario. ${ }^{97}$

A su vez, al identificar los desarrollos en materia de necesidad en la OMC, el tribunal terminó aplicando un régimen de necesidad mucho más favorable al Estado, pues en la OMC, las nociones de "medida indispensable", "única medida posible", y "necesidad” son razonablemente más laxas que la interpretación que se puede encontrar en otros laudos del CIADI mencionados anteriormente:

193. Con respecto a la prueba de la necesidad para los fines de aplicación de excepción general del artículo XX del GATT, está bien establecido que:

...El alcance de la palabra "necesario" no se limita a aquellas medidas que son "indispensables" o "de fuerza mayor" o "inevitables". Las medidas que son indispen-

97 Continental Casualty Company v. The Argentine Republic, ICSID Case no. ARB/03/9, 2008 (para las secciones transcritas de este laudo, se utilizaron traducciones libres de los autores y no la versión oficial en español, que si se encontraba disponible online para los otros casos citados). 
sables, de absoluta necesidad o inevitables para lograr el cumplimento, sin duda responden a los requisitos del artículo XX (d). Pero otras medidas, también, pueden caer dentro del ámbito de esta excepción. Tal como se utiliza en el artículo XX (d), el término "Necesario" se refiere a nuestro juicio a una variedad de grados de necesidad. En un extremo de esta línea "necesarias" se entiende como "indispensables"; en el otro, es "necesaria” en el sentido de que "contribuye a”. Consideramos que una medida "necesaria” está, en esta línea, situada significativamente más cerca del polo de lo "indispensable" que del polo opuesto de lo que simplemente "contribuyente".

194. Para fines de determinar si una medida que no es indispensable, puede no obstante ser "necesaria": La necesidad de una medida debe ser determinada a través de "un proceso de peso y equilibrio de factores", que generalmente incluye la evaluación de los siguientes tres factores: la importancia relativa de los intereses o valores promovidos por las medidas impugnadas, la contribución de la medida a la realización de los fines perseguidos por ésta y la repercusión restrictiva de la medida al comercio internacional. ${ }^{98}$

Del laudo se colige finalmente que la interpretación dada por el tribunal a la aplicación de la necesidad en el contexto de la OMC, conlleva a la construcción de un proceso cercano al de la ponderación, ${ }^{99}$ donde, a diferencia de la aplicación dada por otros laudos a la norma consuetudinaria, la tarea no es establecer si la medida era "la única medida posible"; lo que constituye una altísima carga para el Estado, sino por el contrario, realizar un balance entre la adecuación de la medida a su finalidad, el interés a proteger y el impacto de la medida en el comercio: una carga menor para el Estado.

\section{CONCLUSIONES}

De los casos anteriormente estudiados, se pueden finalmente extraer las siguientes reflexiones generalizables a nivel sustantivo, sobre las consecuen-

98 Continental Casualty Company v. The Argentine Republic, ICSID Case no. ARB/03/9.

99 Sticca, María Alejandra, "El estado de necesidad como causa de exclusión de ilicitud: el caso Continental c. República Argentina”, Anuario - La Ley. Buenos Aires, Córdoba, núm. 11, 2008, pp. 393-411 
Esta revista forma parte del acervo de la Biblioteca Jurídica Virtual del Instituto de Investigaciones Jurídicas de la UNAM

cias atadas a las distintas formas de invocar el estado de necesidad en materia de inversión y las implicaciones de tal defensa en las posibles decisiones de los tribunales.

\section{Alcances del estado de necesidad como norma consuetudinaria}

El régimen consuetudinario de la necesidad es ampliamente utilizado en el CIADI, tanto para el establecimiento del estado de necesidad, como para la prueba de la existencia o no de sus límites materiales. ${ }^{100}$ Aun así, de los casos se desprende que el artículo 25 del Proyecto no fue aplicado de forma autónoma e, incluso, haberlo aplicado sin proceder a continuación a realizar un estudio profundo del artículo del TBI relativo a la necesidad, en algunos de ellos conllevó la anulación del laudo.

Lo anterior merece varias reflexiones en materia de fuentes: en primer lugar, el artículo 42 del Convenio del CIADI permite la utilización del régimen del Proyecto para darle contenido a las normas delTBI cuando éstas se refieran a necesidad sin definirla plenamente. En segundo lugar, este mismo artículo deja abierta la puerta para la aplicación de la necesidad desde su codificación en el Proyecto de la Comisión de Derecho Internacional, como costumbre internacional en materia de responsabilidad internacional, aun si elTBI no incluye una norma habilitante de aplicación del Estado de necesidad (numeral (1) del artículo 42 del Convenio).

Si bien la posibilidad de invocar la necesidad en el régimen de inversiones no queda cerrada por no existir norma relativa a ello en el TBI, lo que sí debe aclararse es que el efecto será distinto: de aplicarse la norma consuetudinaria de necesidad en ausencia de norma en el TBI, lo que ocurrirá es una clásica exclusión de ilicitud, como bien lo desarrolla el Proyecto, pero nunca una completa exclusión de responsabilidad, la cual sólo es posible si el TBI expresamente habilita al estado de necesidad para tener ese efecto.

En ese sentido, una aplicación directa de la necesidad del Proyecto, ${ }^{101}$ como norma consuetudinaria y no como ayuda concomitante a la aplicación

100 Sloane, Robert D., "On the Use and Abuse of Necessity in the Law of State Responsibility”, American Journal of International Law, 106.3, 2012, p. 449.

101 Weiss, Edith Brown, "Invoking State Responsibility in the Twenty-First Century", American Journal of International Law, 2002, pp. 798-816. 
e interpretación de la norma del TBI, implicaría, por lo menos, 1) que el Estado tendría que reanudar el cumplimiento delTBI tan pronto le sea posible; 2) que todo exceso en la necesidad será un hecho ilícito autónomo, y 3 ) que la exclusión de ilicitud no lo exime del pago de indemnización, que deberá acomodarse a los parámetros de reparación estipulados en el proyecto y aquellos propios delTBI, que en esa materia podría ser fuente primaria. ${ }^{102}$

Adicionalmente, al aplicarse directamente la necesidad del Proyecto y de no existir norma convencional al respecto, como lo muestran los laudos, el Estado quedará supeditado a los estándares de "no otro camino" frente a la medida y a la "prueba de la no contribución a la crisis", ambas producto de la consagración de la causal en términos negativos y casi restrictivos desde los trabajos de la Comisión.

2. Alcances del estado de necesidad como potestad bajo un tratado bilateral de inversión

Sin duda alguna, los casos aquí estudiados y sus controversias, fueron posibles sólo con la presencia del artículo relativo a la necesidad en el TBI en cuestión y sus dificultades de redacción e interpretación.

Los laudos enseñan que la aplicación de este tipo de normas, si bien puede aunarse a la del Proyecto para complementar su interpretación (o a las de la OMC, como se vio en el Caso Continental), no debe obviarse si no quiere arriesgarse el laudo a su anulación: las normas relativas a necesidad en losTBI deben ser aplicadas, pero ante todo, requieren un mayor desarrollo de sus propios límites y contenidos materiales.

El diseño de la norma convencional también puede regular los "intereses del Estado" aceptados en la causal, para no quedar los tribunales sólo supeditados al interés de la supervivencia o la existencia del Estado, que ya hizo carrera en el CIADI, como lo explicamos arriba.

La no aplicación de la norma convencional implicaría la anulación del laudo por virtud de la causal de no aplicación del derecho. En materia de responsabilidad y daños, los efectos son ampliamente distintos a los de la necesidad meramente consuetudinaria. Así, de encontrarse una norma en

102 Shelton, Dinah, "Righting Wrongs: Reparations in the Articles on State Responsibility", American Journal of International Law, 2002, pp. 833-856. 
Esta revista forma parte del acervo de la Biblioteca Jurídica Virtual del Instituto de Investigaciones Jurídicas de la UNAM

el régimen bilateral de inversión que faculte al Estado a tomar medidas en virtud de la necesidad, él podría quedar excluido no sólo de ilicitud (sanción, violación del TBI), sino que además, podría quedar excluido de toda responsabilidad, pues sus medidas ya no sólo recaen en una exclusión de ilicitud, sino son actos permitidos por el TBI, que entrarían en sus facultades normales, o que constituyen excepciones permitidas dentro del mismo régimen.

Finalmente, persiste el debate sobre el efecto de la carga de la prueba de los límites a la causal de la exclusión de ilicitud en la responsabilidad del Estado, pues los laudos y los procesos de anulación aún se dividen entre solicitarle al Estado que pruebe su no contribución a la crisis para poder invocar la causal de exclusión de ilicitud de estado de necesidad, u optar por solicitarle a la parte demandante, el inversionista, que para desvirtuar la necesidad invocada por el Estado, sean ellos quienes prueben la contribución del Estado a la crisis y la no adecuación de las medidas tomadas para solucionarla.

\section{BIBLIOGRAFÍA MÍNIMA}

ABELLO, Ricardo, "La costumbre como fuente de derecho internacional: una caja imposible de cerrar", Derecho internacional: varias visiones un maestro. Liber amicorum en Homenaje a Marco Gerardo Monroy Cabra, Universidad Colegio Mayor de Nuestra Señora del Rosario, 2015.

Ago, Roberto, Addendum to the Eighth Report on State Responsibility. UN Doc. A/CN.4/318/Add.5-7, 29 February, 10 and 19 June 1980, Nueva York, International Law Commission, 1980.

ÁlvareZ-JimÉnEZ, Alberto, "Foreign Investment Protection and Regulatory Failures as States' Contribution to the State of Necessity under Customary International Law. A New Approach Based on the Complexity of Argentina's 2001 Crisis", Journal of International Arbitration, núm. 27.2, 2010.

AREvalo, Walter, "Responsabilidad internacional del Estado por hechos internacionalmente ilícitos: las causales de exclusión de ilicitud, su contenido y escenarios de aplicación", Derecho internacional: varias visiones un 
Esta revista forma parte del acervo de la Biblioteca Jurídica Virtual del Instituto de Investigaciones Jurídicas de la UNAM

maestro. Liber amicorum en Homenaje a Marco Gerardo Monroy Cabra, Universidad Colegio Mayor de Nuestra Señora del Rosario, 2015.

BALDWIN, Edward et al., "Limits to Enforcement of ICSID Awards", Journal of International Arbitration, 23.1, 2006.

BOED, Roman, "State of Necessity as a Justification for Internationally Wrongful Conduct", Yale Hum. Rts. \& Dev. LJ, 3, 2000.

Boyle, Alan, "The Gabčíkovo-Nagymaros Case: New Law in Old Bottles”, Yearbook of International Environmental Law, 8.1,1998.

COlacrai, Miryam, "El legado hobbesiano acerca del «estado de naturaleza» en los estudios de relaciones internacionales de Hans Morgenthau y Raymond Aron. Matices y diferencias", Revista de Historia Actual, 1, 2010.

COMISIÓn DE DERECho InTERnACIONAL, "Draft Articles on Responsibility of States for Internationally Wrongful Acts with Commentaries”, Yearbook of the International Law Commission, vol. II, Part Two, 2001.

Cortes Marin, J. M., "El estado de necesidad en materia económica y financiera”, Anuario Español de Derecho Internacional, núm. XXV, 2009.

CRAWFORD, James, "Revising the Draft Articles on State Responsibility", European Journal of International Law, núm. 10.2,1999.

Di RosA, Paolo, "The Recent Wave of Arbitrations Against Argentina under Bilateral Investment Treaties: Background and Principal Legal Issues", The University of Miami Inter-American Law Review, 2004.

Downs, George W. y Jones, Michael, "Reputation, Compliance, and International Law”, The Journal of Legal Studies, 31.S1, 2002.

FALKOF, Greg, "«State of Necessity» Defence Accepted in LG\&E v. Argentina ICSID Tribunal”, Transnational Dispute Management (TDM), 3.5, 2006. FORJI, Amin George, "Drawing the Right Lessons from ICSID Jurisprudence on the Doctrine of Necessity", Arbitration: The International Journal of Arbitration, Mediation and Dispute Management, 76.1, 2010.

Friedland, Paul y Brumpton, Paul, "Rabid Redux: The Second Wave of Abusive ICSID Annulments", American University International Law Review, 27.4, 2012.

GinsBurG, Robert, "Political Risk Insurance and Bilateral Investment Treaties: Making the Connection", The Journal of World Investment \& Trade, 14.6, 2013.

GOLDSMITH, Jack L. y POSNER, Eric, "A Theory of Customary International Law”, The University of Chicago Law Review, 1999. 
Esta revista forma parte del acervo de la Biblioteca Jurídica Virtual del Instituto de Investigaciones Jurídicas de la UNAM

GÓmEZ-Robledo, Antonio, "Le ius cogens international: sa genèse, sa nature, ses fonctions", Recueil des Cours. Académie de Droit International de La Haye, 1982.

Gourgourinis, Anastasios, "General/Particular International Law and Primary/Secondary Rules: Unitary Terminology of a Fragmented System”, European Journal of International Law, 22.4, 2011.

HeAthCote, Sarah, "State of Necessity", Oxford Bibliographies Online: International Law, disponible en: http:/ / www.oxfordbibliographies.com/view/document/obo-9780199796953/obo-9780199796953-0025.xml.

JACOBS, Becky L., "Pesification and Economic Crisis in Argentina: The Moral Hazard Posed by a Politicized Supreme Court", The University of Miami Inter-American Law Review, 2003.

KASENETZ, Eric David, “Desperate Times Call for Desperate Measures: The Aftermath of Argentina's State of Necessity and the Current Fight in the ICSID”, George Washington International Law Review, 41, 2009.

KIM, Dohyun, “Annulment Committee’s Role in Multiplying Inconsistency in Icsid Arbitration: The Need to Move Away from an Annulment-Based System”, The NYUL Rev, 86, 2011.

KraWIEC, Daniel A., "Sempra Energy International v. the Argentine Republic: Reaffirming the Rights of Foreign Investors to the Protection of ICSID Arbitration”, Law \& Bussiness Review American University, 15, 2009.

KuRTZ, Jürgen, “Adjudging the Exceptional at International Investment Law: Security, Public Order and Financial Crisis", International and Comparative Law Quarterly, 59.02, 2010.

LAursen, Andreas, "Use of Force and (the State of) Necessity", The Vanderbilt Journal of Transnational Law. 37, 2004, pp. 485.

Lauterpacht, Elihu y Bethlehem, Daniel, "The Scope and Content of the Principle of Nonrefoulement: Opinion”, Refugee Protection in International Law: UNHCR's Global Consultations on International Protection, 2003.

MAGENIS, Sean D., "Natural Law as the Customary International Law of Self-Defense”, Boston University International Law Journal, 20, 2002.

ManCINA, Emily F., "Sinners in the Hands of an Angry God: Resurrecting the Odious Debt Doctrine in International Law”, GeorgeWashington International Law Review, 36, 2004.

MARTíneZ, Elizabeth, "Understanding the Debate over Necessity: Unanswered Questions and Future Implications of Annulments in the Argentine Gas Cases", Duke J. Comp. \&Int'1 L, 23, 2012. 
Esta revista forma parte del acervo de la Biblioteca Jurídica Virtual del Instituto de Investigaciones Jurídicas de la UNAM

Reichert-FaCilides, Daniel, "Down the Danube: The Vienna Convention on the Law of Treaties and the Case Concerning the Gabcikovo-Nagymaros Project", International and Comparative Law Quarterly, 47.04, 1998.

REINISCH, August, Necessity in International Investment Arbitration-An Unnecessary Split of Opinions in Recent ICSID Cases-Comments on CMS v.Argentina and LG\&E v. Argentina, 2007.

Rosell, José, "The CMS Case: A Lesson for the Future?", Journal of International Arbitration, 25.4, 2008.

SCHILL, Stephan W., "From Calvo to CMS: Burying an International Law Legacy? Argentina's Currency Reform in the Face of Investment Protection: The ICSID Case CMS v. Argentina", Transnational Dispute Management (TDM), 3.2, 2006.

SCHREUER, Christoph, "From ICSID Annulment to Appeal Half Way Down the Slippery Slope", The Law and Practice of International Courts and Tribunals, 10.2, 2011.

SHELTON, Dinah, "Normative Hierarchy in International Law", American Journal of International Law, 2006.

, "Righting Wrongs: Reparations in the Articles on State Responsibility”, American Journal of International Law, 2002.

SlOANE, Robert D., "On the Use and Abuse of Necessity in the Law of State Responsibility”, American Journal of International Law, 106.3, 2012.

SOMmer, Christian G., "La aplicación de estándares de protección de inversiones extranjeras. Una mirada desde los casos argentinos", Anuario Colombiano de Derecho Internacional-ACDI, 6, 2013.

SORnARAJAh, Muthucumaraswamy, "State Responsibility and Bilateral Investment Treaties", Journal of World Trade, 20.1, 1986.

STICCA, María Alejandra, "El estado de necesidad como causa de exclusión de ilicitud: el caso Continental c. República Argentina”, Anuario-La Ley. Buenos Aires, Córdoba, núm. 11, 2008.

Tratado entre la República Argentina y los Estados Unidos de América sobre Promoción y Protección Recíproca de Inversiones, 1991 (texto auténtico).

United NATIONS, Reports of International Arbitral Awards, vol. III (United Nations publication. Sales No. 1949.V.2), p. 1405.

VON STADEN, Andreas, "Towards Greater Doctrinal Clarity in InvestorState Arbitration: The CMS, Sempra, and Enron Annulment Decisions”, Czech Yearbook of International Law, núm. 2, 2011. 
WAIBEL, Michael, “Two Worlds of Necessity in ICSID Arbitration: CMS and LG\&E”, Leiden Journal of International Law, 20.03, 2007.

WaLD, Arnoldo, "Estado de necesidad en Enron, Sempra y CMS: extralimitación manifiesta de las facultades como causal de anulación", Anuario Latinoamericano De Arbitraje, "Sistema de Anulación de los Laudos CIADI", núm.1, 2011.

, "El estado de necesidad en arbitraje del CIADI", Latin Arbitration Law, núm. 1, 2014, disponible en: http: / / www.latinarbitrationlaw.com/elestado-de-necesidad-en-arbitraje-del-ciadi / (fecha de consulta: noviembre).

WeISS, Edith Brown, "Invoking State Responsibility in the Twenty-First Century", American Journal of International Law, 2002.

Wilson, Michael, "Enron v. Argentina Annulment Decision: Moving a Bishop Vertically in the Precarious ICSID System", The U. Miami Inter-Am. L. Rev, núm. 43, 2011. 